\title{
POSTTRAUMATIC STRESS DISORDER TREATMENT PREFERENCE: \\ COGNITIVE PROCESSING THERAPY, PROLONGED EXPOSURE THERAPY, OR PHARMACOTHERAPY?
}

\author{
by \\ Shankari Sharma \\ Bachelor of Arts (Hons), Specialization in Psychology, Minor in Criminology, \\ University of Ottawa, Ottawa, ON, 2011. \\ A thesis presented to Ryerson University \\ in partial fulfillment of the requirements for the Degree of \\ Master of Arts \\ in the Program of Psychology.
}

Toronto, Ontario, Canada, 2013

(C) Shankari Sharma 2013 


\section{AUTHOR'S DECLARATION FOR ELECTRONIC SUBMISSION OF A THESIS}

I hereby declare that I am the sole author of this thesis. This is a true copy of the thesis, including any required final revisions, as accepted by my examiners.

I authorize Ryerson University to lend this thesis or dissertation to other institutions or individuals for the purpose of scholarly research.

I further authorize Ryerson University to reproduce this thesis or dissertation by photocopying or by other means, in total or in part, at the request of other institutions or individuals for the purpose of scholarly research.

I understand that my thesis may be made electronically available to the public. 


\title{
POSTTRAUMATIC STRESS DISORDER TREATMENT PREFERENCE: \\ COGNITIVE PROCESSING THERAPY, PROLONGED EXPOSURE THERAPY, OR PHARMACOTHERAPY?
}

\author{
Shankari Sharma \\ Psychology \\ Ryerson University
}

Of the available treatments for Posttraumatic Stress Disorder (PTSD), Cognitive Processing Therapy (CPT), Prolonged Exposure Therapy (PE), and pharmacotherapy are the protocols with the strongest research support. To investigate individuals' preferences for treatment, participants were asked to read descriptions of CPT, PE, and pharmacotherapy, choose which one they think they would prefer should they require treatment, and rate their perceptions of treatment credibility. Two simultaneous studies were conducted: one with undergraduate and the other with online participants, and the latter had higher scores on measures of symptom distress. CPT was the first choice in both studies and was considered the most credible option. Undergraduate participants preferred PE as their second choice, while online participants picked pharmacotherapy. Undergraduate participants found PE to be more credible than pharmacotherapy, while online participants found them to be equally credible. Both groups chose psychotherapy alone as their first choice when given the option to combine psychotherapy and pharmacotherapy. 
There are many people without whom this project would never have gotten underway, let alone been completed. First and foremost, I owe a great debt of gratitude to my supervisors, Drs. Maya Roth and Candice Monson, who took me on as their student midway through my Master's degree and allowed me to embark on a project that would require primary data collection from multiple sources. Dr. Roth's unwavering encouragement, considered feedback, genuine caring and good humour were invaluable throughout this year, and I very much look forward to continued graduate study under her supervision in the years to come. Dr. Monson's keen methodological insight and problem-solving ability have been crucial in the development and completion of this project, and I thank her for being there when it really counted.

To all the students who answered my questions, calmed my nerves, and had faith in me when my confidence wavered, you have my sincerest gratitude. You are: Matthew King, Sonya Wanklyn, Philippe Shnaider, Leanne Wilkins, Jennifer Rouse, Nicole Cormier, Sara Cowan, Amy Usher, Skye Stephens, and Sandra Oziel.

Without the guidance and teaching of my professors at the University of Ottawa, I would not be here today. Special thanks go to Dr. Heather Orpana, my undergraduate thesis supervisor, for whetting my appetite for research and being a fantastic human being; Dr. Peggy Kleinplatz, for making her classes truly eye-opening and engaging; and Dr. Barry Jessup, my first year linear algebra professor, who reminded me that the road to success is paved with hard work and dedication.

Laura Rogers, Heather Ashford, and Harbir Anand, as always, you have remained my touchstones. Laura, you showed me that it is worth it to dream big and to hold on to your goals even through the tough times. Heather and Harbir, you are my chosen family, and when I count my blessings, I count you twice.

Finally, thanks to my parents, Madhu and Gan Sharma, and the rest of my family, who have always believed in me, who have sacrificed continually for me, and who have loved me fiercely. I am eternally grateful to and in awe of you. 


\section{Table of Contents}

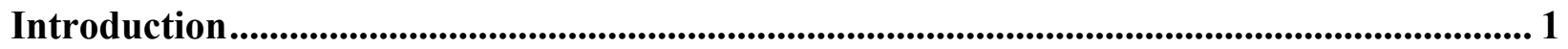

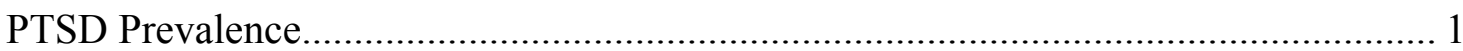

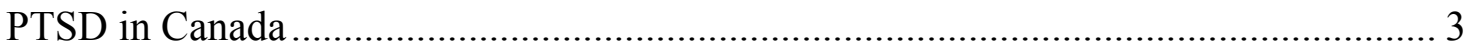

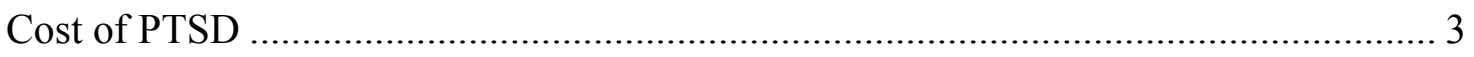

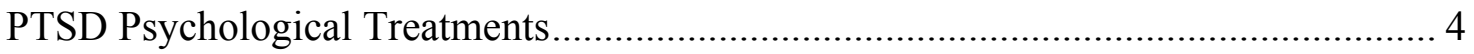

PTSD Pharmacological Treatments .................................................................... 7

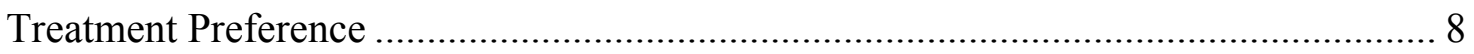

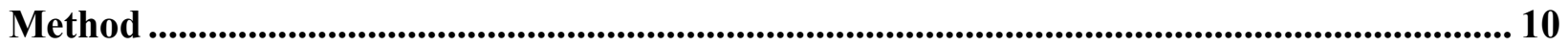

Study 1: Undergraduate Recruitment................................................................... 10

Study 2: Online Recruitment............................................................................... 10

Procedure and Measures..................................................................................... 11

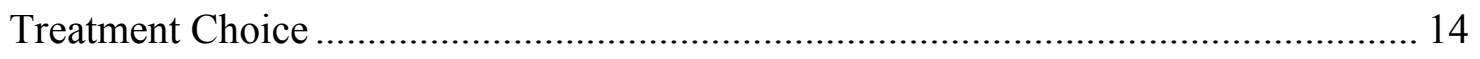

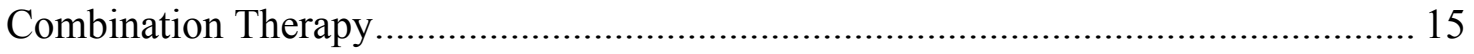

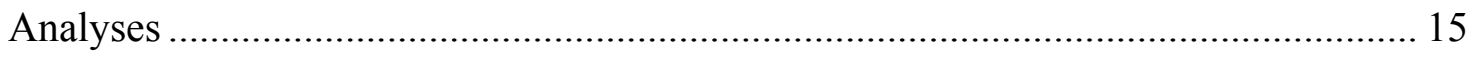

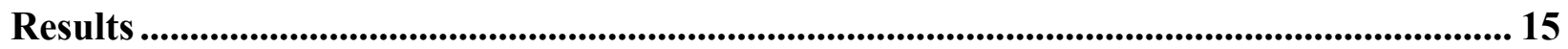

Study 1: Undergraduate Participant Characteristics.................................................... 15

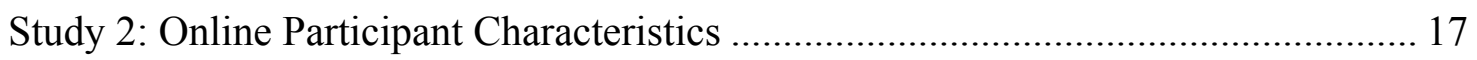

Study 1: Undergraduate Sample Treatment Preferences and Credibility Ratings ........ 19

Study 2: Online Sample Treatment Preferences and Credibility Ratings ....................... 20

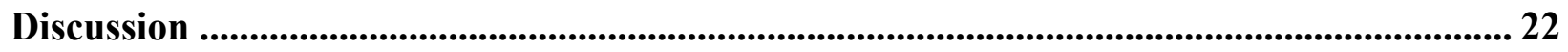

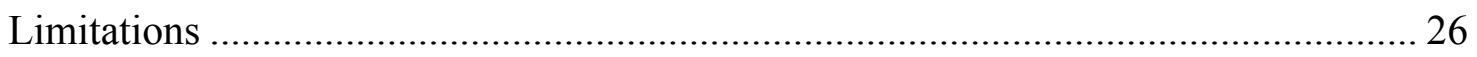

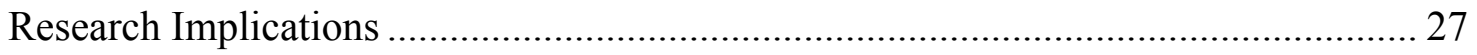


Clinical Implications .

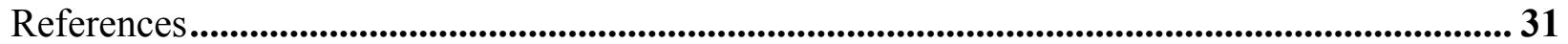




\section{List of Tables}

Table 1. Word Counts and Readability Statistics of Treatment Descriptions ................ 13

Table 2. Study 1: Undergraduate Sample Trauma Exposure..................................... 16

Table 3. Study 2: Online Sample Trauma Exposure................................................ 17

Table 4. Mental Health Symptomatology by Recruitment Source ............................... 18 


\section{List of Figures}

Figure 1. Study 1: Undergraduate Sample Treatment Preference................................. 19

Figure 2. Study 1: Online Sample Treatment Preference............................................ 21 


\section{List of Appendices}

Appendix A. Depression Anxiety Stress Scales (DASS-21)......................................... 43

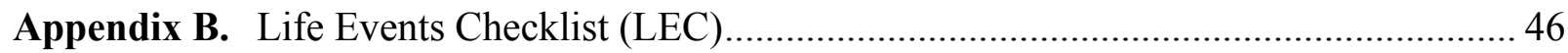

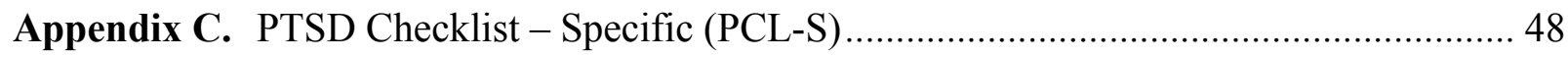

Appendix D. Description of Cognitive Therapy, Exposure Therapy, and Pharmacotherapy . 51

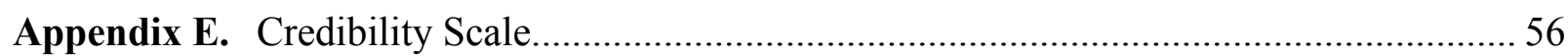

Appendix F. Personal Reactions to the Rationales .................................................. 57 
Exposure to traumatic events - such as war, a life-threatening accident, sexual assault, child abuse or neglect, natural disasters, violence or acts of terrorism—can result in a wide variety of psychological and physiological sequelae. Consistent with the symptoms included in the Diagnostic and Statistical Manual of Mental Disorders (4th ed., text rev.; DSM-IV-TR; American Psychiatric Association, 2000), they can include distressing and intrusive reexperiencing of the event (i.e., intrusive recollections, persistent flashbacks or nightmares, intense psychological distress or physiological reactivity when exposed to trauma-related cues), avoidance or numbing (i.e., cognitive avoidance, avoidance of situations or people that are reminiscent of the trauma, inability to recall aspects of the traumatic event, diminished interest or participation in significant activities, feelings of detachment or estrangement from others, restricted range of affect, sense of foreshortened future), and increased arousal (i.e., sleep disruptions, irritability or anger, difficulty concentrating, hypervigilance, exaggerated startle response). Fortunately for most people, these distressing symptoms remit over time (Rothbaum, Foa, Riggs, Murdock, \& Walsh, 1992). For others, a substantial minority, they can persist for months and years (Gray et al., 2004), causing clinically significant distress and impairment in social, occupational, or other areas of functioning, and lead to the presence of Posttraumatic Stress Disorder (PTSD). PTSD typically exhibits a chronic course, with approximately $40 \%$ of sufferers experiencing significant symptoms 10 years post-onset (Kessler, Sonnega, Bromet, Hughes, \& Nelson, 1995).

\section{PTSD Prevalence}

There have been numerous studies assessing the prevalence rates of PTSD in the general population. The earliest of these studies, carried out as part of the Epidemiological Catchment Area (ECA) program in Missouri and North Carolina, used Diagnostic and Statistical Manual of 
Mental Disorders (3rd ed.; DSM-III; American Psychiatric Association, 1980) criteria and measured the prevalence of PTSD resulting from trauma related to the Vietnam War and being mugged (Davidson, Hughes, Blazer, \& George, 1991; Helzer, Robins, \& McEvoy, 1987). The ECA survey used the Diagnostic Interview Schedule (DIS; Robins \& Helzer, 1985) and found lifetime prevalence to be $1 \%$ in St. Louis and $1.3 \%$ in North Carolina. Using DSM-III-R (APA, 1987) criteria, Resnick and colleagues (1993) conducted a national telephone survey of women and found that while $69 \%$ of them had been exposed to a traumatic event, $12.3 \%$ of respondents (17.9\% of those exposed to trauma) had a lifetime history of PTSD, a large increase in prevalence compared to the previous two studies using DSM-III criteria. During the past 25 years, several other studies were carried out in the United States to assess PTSD prevalence, ageof-onset, and course (Breslau, Davis, Andreski, \& Peterson, 1991; Breslau, Kessler, \& Chilcoat, 1998; Breslau, Wilcox, Storr, et al. 2004; Kessler et al., 1995; Kessler, Berglund, Demler, Jin, \& Walters, 2005).

The two most rigorous and recent studies of the prevalence of PTSD in the United States, however, come from the National Comorbidity Study (NCS) and National Comorbidity StudyReplication (NCS-R; Kessler et al., 1995; Kessler, Chiu, Demler, \& Walters, 2005). The NCS surveyed 5877 respondents across the United States, aged 15-54, and found that of the $60.7 \%$ of men and $51.2 \%$ of women that had experienced at least one traumatic event, $8.2 \%$ of men and 20.4\% of women had PTSD as defined by DSM-III criteria. The NCS-R showed that the 12month incidence of PTSD, as opposed to the previously measured lifetime prevalence, was $3.5 \%$ in the general population. Differences in assessment criteria, respondent characteristics, and traumatic events probed across the large number of prevalence studies make it difficult to 
compare results. However, aside from the earliest studies that used DSM-III criteria, PTSD prevalence rates are high in the general population of the United States.

\section{PTSD in Canada}

In Canada, there have only been two studies examining the prevalence of PTSD. The first, by Stein and colleagues (1997), only measured one-month PTSD prevalence rates in Winnipeg, MB; $1.2 \%$ of men and $2.7 \%$ of women met the full criteria for PTSD as defined by DSM-IV criteria. Van Ameringen and colleagues (2008) used a nationally representative sample and found that while $75.9 \%$ of the population reported having experienced a traumatic event, the lifetime and one-month prevalence rates of DSM-IV PTSD were $9.2 \%$ and $2.4 \%$ respectively, largely commensurate with the NCS and NCS-R.

\section{Cost of PTSD}

There are significant personal and societal costs associated with PTSD. In the United States, PTSD is associated with 3.6 days of work loss or cutback per month, which translates to an annual productivity loss greater than $\$ 3$ billion (Kessler, 2000). In addition, NCS respondents (Kessler et al., 1995) with PTSD had significantly elevated odds (standardized for sociodemographics) for college or high school failure, teenage childbearing, and current unemployment at the time of interview (Kessler, 2000), suggesting that the abovementioned productivity loss would be even higher if the monetary cost of lost life course opportunities were included in the estimate. Prevalence of PTSD symptoms is also associated with increased healthcare utilization and higher rates of other psychological and physical health problems (Davidson, Swartz, Stork, et al., 1985; Engdahl, Dikel, Eberly, \& Blank, 1998; Green, Lindy, Grace, \& Gleser, 1989; Kilpatrick \& Resnick, 1992; Shore, Vollmer, \& Tatum, 1989; Sierles, Chen, McFarland, \& Taylor, 1983). 
In addition to the increased rates of prevalence of physical and psychological health problems, there is a robust relationship between increased suicidal behaviours and diagnosis of PTSD, both in clinical (Ferrada-Noli, Asberg, Ormstad, Lundin, \& Sundbom, 1998; Kotler, Iancu, Efroni, \& Amir, 2001) and community (Davidson, Hughes, Blazer, \& George,1991; Helzer, Robins, \& McEvoy, 1987; Kessler et al., 1995; Wunderlich, Bronisch, \& Wittchen, 1998) samples. Oquendo and colleagues (2000) found evidence of this relationship, even after adjusting for the presence of major depression, substance abuse, and cluster B personality disorders, and Sareen and colleagues (2005) replicated this finding in a nationally representative sample in Canada. Increasing evidence suggests, however, that each comorbid mental health disorder represents independent risk for suicidal behavior (Dobry \& Sher, 2012). The risk for psychological comorbidities with PTSD is well established (Galatzer-Levy, Nickerson, Litz, \& Marmar, 2013), the research on the association between PTSD and physical health problems has likewise shown significant associations (Qureshi, Pyne, Magruder, Schulz, \& Kunik, 2009), and PTSD has been found to have the highest cost of all anxiety disorders (Greenberg et al., 1999). As such, the effective treatment of PTSD remains an exigent public health concern.

\section{PTSD Psychological Treatments}

Multiple evidence-based psychological treatments are currently available for the individual (i.e., non-group or non-couple) treatment of PTSD and extensive research has been conducted on their efficacy. Currently, the strongest research support is for trauma-focused psychotherapies, such as trauma-focused Cognitive-Behavioural Therapy (TFCBT) or Eye Movement Desensitization and Reprocessing (EMDR; Bisson \& Andrew, 2009; Bisson, Ehlers, Matthews, Pilling, Richards, \& Turner, 2007; Bradley, Greene, Russ, Dutra, \& Westen, 2005; Cloitre, 2009; Ehlers, Bisson, Clark, Creamer, Pilling, Richards, Schnurr, Turner, \& Yule, 2010; 
Seidler \& Wagner, 2006; van Etten \& Taylor, 1998). Cognitive-Behavioural Therapies (CBTs) are one of the most effective treatments for PTSD, with findings indicating that $42-80 \%$ of clients show significant improvements and 50-70\% no longer meeting criteria for PTSD once treatment is completed (Bradley, Greene, Russ, Dutra, \& Westen, 2005; Foa, Dancu, Hembree, Jaycox, Meadows, \& Street, 1999; Foa, Rothbaum, Riggs, \& Murdock, 1991; Resick, Nishith, Weaver, Astin, \& Feuer, 2002; Tarrier et al., 1999). TFCBT includes psychoeducation about common reactions to trauma, in vivo exposure (direct confrontation of feared situations or activities) and/or imaginal exposure (imagining and retelling the traumatic event) to anxietyprovoking situations and memories related to the trauma, writing and repetitive readings of descriptions of the traumatic event, and cognitive restructuring around issues of blame and guilt, and anxiety management. The two most widely used and researched therapies that fall under the TFCBT umbrella are Prolonged Exposure (PE) Therapy (Foa, Hembree, \& Rothbaum, 2007; Foa \& Rothbaum, 1998; Foa, Rothbaum, Riggs, \& Murdock, 1991) and Cognitive Processing Therapy (CPT; Resick, Monson, \& Chard, 2007; Resick \& Schnicke, 1993).

PE is based on emotional processing theory (Foa, Huppert, \& Cahill, 2006; Foa \& Kozak, 1986; Foa \& McNally, 1996) and predicated upon the assertion that PTSD symptoms result primarily from the development of overgeneralized fear networks in memory, which bring on excessive avoidance and escape behaviours, intense emotions, and negative beliefs. PE has four components: psychoeducation and rationale for treatment, breathing retraining to help clients fully engage with the intense negative emotions associated with the trauma memories, in vivo exposures to safe but avoided trauma reminders, and imaginal exposures to memories of the most distressing traumatic event. The majority of PE sessions focus on imaginal exposure, where the client describes the trauma in first person as if the event were occurring at that time for 45 to 
60 minutes of the 90-minute session, and the client carries out the in vivo exposures in between formal therapy sessions. Several meta-analyses have shown that PE is an effective treatment for PTSD (Benish, Imel, \& Wampold, 2008; Bisson \& Andrew, 2007; Bisson et al., 2007; Seidler \& Wagner, 2006), the most recent of which was conducted by Powers, Halpern, Ferenschak, Gillihan, and Foa (2010) and showed that: (1) PE significantly outperforms wait-list and control conditions on primary PTSD outcome measures, both at post-treatment $(\mathrm{g}=0.77)$ and follow-up $(g=0.41)$, and that (2) PE performs equally well when compared with other active treatments (such as CPT), showing no significant overall differences on primary outcome measures of PTSD at post-treatment $(g=-0.07)$.

CPT is based on a social cognitive theory of PTSD (Resick, Monson, \& Chard, 2008) and predicated upon the theory that, although fear, anger, or sadness can result naturally from traumatic experiences, faulty interpretations of traumas can serve to manufacture emotions such as shame, guilt, humiliation, etc. These faulty interpretations (or stuck points) are of two types: (1) assimilation, where the memory of the trauma is altered to attempt to fit with prior beliefs (e.g., a person who believes that good things happen to good people might interpret the trauma as punishment for being a bad person); and (2) over-accommodation, wherein the interpretation of a traumatic event results in an extreme change in beliefs (e.g., a person who is raped by a man might come to think that "no man can be trusted" in order to feel safer and more in control) or might interpret the experience as validation of a previously-held, extreme negative cognition (e.g., "I previously thought all men were untrustworthy and this proves it"). As such, remembering the trauma or being exposed to traumatic cues results in the experience of intense and distressing emotions from assimilated or over-accommodated beliefs, which serve to maintain PTSD symptoms. CPT has four components: psychoeducation and rationale for 
treatment, becoming aware of thoughts (particularly assimilations and over-accommodations) and feelings (both natural or manufactured) related to the traumatic memories, skill building to challenge assimilated and/or over-accommodated cognitions, and generating more balanced cognitions. CPT sessions last for 50 minutes and involve: (1) the client reading out written accounts of the traumatic event and its impact, and (2) talking about the client's assimilated and over-accommodated beliefs and generating more balanced ones. Several studies have documented the efficacy of CPT in the treatment of PTSD (Chard, 2005; Monson et al., 2006; Resick et al., 2002; Resick et al., 2008), and head-to-head comparisons of CPT and PE have shown both therapies to be equally efficacious in the treatment of PTSD (Galovski, Monson, Bruce, Resick, 2009; Resick et al., 2012). Further, follow-ups at 3 months, 9 months, and 5+ years post-treatment show that the substantial decreases in symptoms are maintained throughout the follow-up periods; no significant differences were observed between those treated with CPT and PE at these follow-ups (Resick, Williams, Suvak, Monson, \& Gradus, 2012).

\section{PTSD Pharmacological Treatments}

Several pharmacotherapy options have been found to be useful for the treatment of PTSD, and these include selective serotonin reuptake inhibitors (SSRIs), tricyclic antidepressants (Davidson et al., 1990; Davidson et al., 2006a; Davidson et al., 2006b), dual serotonin and noradrenaline re-uptake inhibitors (Davidson et al., 2006; Davidson et al., 1990; Frank et al., 1988), monoamine oxidase inhibitors (MAOIs; Frank et al., 1988), and reversible monoamine oxidase A inhibitors (RIMAs; Onder et al., 2006). Other classes of medications used for the treatment or management of PTSD symptoms include anticonvulsants, benzodiazepines, secondgeneration antipsychotics, 2-Adrenergic agonists and -adrenergic blockers (for a review, see

Ravindran \& Stein, 2010; Steckler \& Risbrough, 2012). SSRIs are the first-line pharmacological 
interventions for the treatment of PTSD, and they have been shown to be effective both in the reduction of symptom severity and relapse prevention (Van der Kolk et al., 1994; Connor et al., 1999; Brady et al., 2000; Martenyi et al., 2002a; Martenyi et al., 2002b; McRae et al., 2004; Onder, Tural, \& Aker, 2006); sertraline and paroxetine (two types of SSRIs) are the only medications currently approved by the Federal Drug Agency (FDA) in the United States and the European Medicines Agency (EMA) for the treatment of PTSD. Approximately $60 \%$ of those who suffer from PTSD symptoms respond to SSRI therapy, and in 20-30\% of patients, SSRIs can result in full remission (Stein, Kline, \& Matloff, 2002; Zohar et al., 2002). Some evidence suggests, however, that certain populations (such as combat veterans) do not respond as well to SSRI intervention (Benedek et al., 2009). Together, trauma-focused CBTs and pharmacological treatments remain the most effective treatments available for PTSD.

\section{Treatment Preference}

Although efficacious psychosocial and psychopharmacological treatments are available for the treatment of PTSD, we currently know little about the factors that might moderate the efficacy of these treatments. Individual preference for treatment modality is one such factor worthy of consideration, particularly if individuals differ markedly in their preferences. Current research to gauge individuals' preferences for PTSD treatment has focused almost exclusively on asking respondents to choose between: (1) medication and counseling (Roy-Byrne, Berliner, Russo, Zatzick, \& Pitman, 2003), and (2) sertraline and PE (Angelo, Miller, \& Zoellner, 2008; Cochran, Pruitt, Fukuda, Zoellner, \& Feeny, 2008; Feeny, Zoellner, \& Kahana, 2009; Feeny, Zoellner, Mavissakalian, \& Roy-Byrne, 2009; Pruitt, Zoellner, Feeny, Caldwell, \& Hanson, 2012; Zoellner, Feeny, \& Bittinger, 2009). Results of these studies show that respondents overwhelmingly choose PE over sertraline when given the choice. 
Only one study has surveyed non-undergraduate students, but restricted the sample to law enforcement personnel rather than a more generally trauma-exposed sample (Becker et al., 2009). Their study offered six choices (CPT, PE, sertraline, psychodynamic, a brief eclectic therapy developed specifically for law enforcement personnel, and EMDR) and found that CPT, followed by PE, were participants' top choices. Presently, no data is available on the treatment preferences of individuals exposed to a more representative sample of the traumatic stressors. Furthermore, no data is presently available on individuals' treatment preferences when asked to choose between empirically validated TFCBTs and pharmacotherapy in general, as opposed to one type of SSRI, such as sertraline. The present study will extend the work done by Becker and colleagues (2009).

The current study asks participants to imagine that they are suffering from PTSD symptoms and choose what type of treatment they think would be most effective and credible. Treatment choices presented to participants were exposure therapy (ET; description based on $\mathrm{PE}$ ), cognitive therapy (CT; description based on CPT), and medication therapy (MT; description based on current pharmacotherapy for PTSD literature). Two simultaneous studies were conducted, one in which participants were recruited from the undergraduate psychology student pool at Ryerson University, and another in which participants were recruited from online traumaand PTSD-related support and discussion groups. Based on prior research, it was hypothesized for both studies that: (1) individuals will choose CT as their first choice, ET as their second choice, and MT as their last choice for treatment; (2) when given the choice between psychotherapy and pharmacotherapy, individuals will be most likely to choose psychotherapy first, followed by simultaneous combination of psychotherapy and medication and (3) 
individuals will find $\mathrm{CT}$ to be the most credible treatment option, ET to be the second most credible treatment option, and MT to be the least credible treatment option.

\section{Method}

\section{Study 1: Undergraduate Recruitment}

Participants in Study 1 were recruited via the undergraduate Psychology Research Pool at Ryerson University $(N=119)$. Undergraduate students were compensated with course credit (half a credit, as per departmental policy). The mean age of undergraduate participants was 21.92 $(\mathrm{SD}=5.28)$ years. $44(37 \%)$ identified as male and $75(63 \%)$ as female. The Ryerson University Research Ethics Board (REB) approved this study, and REB-approved participation requests were posted on the Ryerson University Psychology Research Pool website.

\section{Study 2: Online Recruitment}

In an effort to recruit a more representative sample of individuals - who had been exposed to a variety of traumatic events, were from a broader range of socio-demographic backgrounds, and were from a larger geographical area than Toronto and surrounding areasparticipants in Study 2 were recruited via online trauma- and PTSD-related support and discussion groups $(N=126)$. Online participants who chose to provide their address were compensated with $\$ 5$ Starbucks gift cards; those who did not want to provide their addresses were allowed to participate, without receiving compensation. The mean age of participants recruited online was $36.57(\mathrm{SD}=13.42)$ years. $29(23 \%)$ identified as male, $96(76.2 \%)$ as female, and $1(0.8 \%)$ as other. The Ryerson University Research Ethics Board (REB) approved this study, and REB-approved participation requests were posted on several online groups that were found through the Google search engine and through Facebook, such as PTSD Forum and the PTSD sections of Psych Forums and eHealth Forum. 


\section{Procedure and Measures}

All prospective participants, regardless of whether they were recruited through the Ryerson University undergraduate pool or online, were asked to click on a hyperlink redirecting them to the PTSD treatment preference study website. Clicking on the link redirected them to the consent page for the study, which contained information on the purpose of the study, the names and contact information for the study investigators, a study description, potential risks and benefits of participation, and individuals' right to withdraw at any time without penalty. Participants who consented to participation were asked their age to confirm that they were adults, whether they could read and write English fluently, and if they resided in Canada or the United States. Individuals over the age of 17, who reported being fluent readers and writers of English and who reported being residents of Canada or the United States were included in the study.

Demographic questions related to sex, employment, education level, income, and prior diagnosis and treatment of PTSD were asked. To assess the prevalence of symptoms of depression, anxiety, and general stress, the Depression Anxiety Stress Scales-21 (DASS-21; Antony, Bieling, Cox, Enns, \& Swinson, 1998; see Appendix A), a measure with 21 items (7 items for each emotional state), were used. Individuals are asked to rate the degree to which items on the scale — such as 'I couldn't seem to experience any positive feeling at all' — applied to them in the past week. The DASS-21 has subscales for the measurement of depression, anxiety, and stress, and the measure is reliable and valid when used to measure these constructs (Antony et al., 1998; Henry \& Crawford, 2005). In a study by Henry and Crawford (2005), the DASS-21 subscale alphas ranged from .88-.90. In the present studies, alphas ranged from 0.84.91 in Study 1 and .86-.93 in Study 2. 
To assess symptoms of PTSD, the Life Events Checklist (LEC; Gray, Litz, Hsu, \& Lombardo, 2004; see Appendix B), a measure used to assess individuals' exposure to potentially traumatic stressors, and the PTSD Checklist-Specific (PCL-S; Blanchard, Jones-Alexander, \& Forneris, 1996; Weathers, Litz, Herman, Huska, \& Keane, 1993; see Appendix C), a self-report measure of the 17 symptoms of PTSD as included in the DSM-IV (APA, 1994), were used. On the LEC, participants were asked whether or not they personally experienced, witnessed or heard about a wide variety of potentially traumatic stressors, such as transportation accidents or assaults. The LEC is a reliable and valid measure used for the assessment of the level of exposure an individual has had to potentially traumatizing events (Gray, Litz, Hsu, \& Lombardo, 2004). Once participants completed the LEC, they were asked to keep the most traumatic event they had experienced in the past in mind while completing the PCL-S, which has been found to be an internally consistent, reliable and valid measure of re-experiencing, avoidance, and hyperarousal symptoms included in the DSM-IV (APA, 1994) criteria for PTSD (Ruggiero, Del Ben, Scotti, \& Rabalais, 2003).

After the initial assessment of demographics and symptoms of psychopathology, participants were asked to read about the types of symptoms and distress that a person with PTSD might experience. They were asked to read the descriptions of CPT, PE, and pharmacotherapy, which were called cognitive therapy, exposure therapy, and medication therapy, respectively (see Appendix D). Descriptions were presented in a counterbalanced order in order to control for order effects, and they included information on the usual duration of treatment, efficacy, techniques used during therapy sessions, homework or out-of-session tasks, and possible side effects or risks. Descriptive content was based on treatment manuals (Foa, Hembree, \& Rothbaum, 2007; Foa \& Rothbaum, 1998; Foa, Rothbaum, Riggs, \& Murdock, 
1991; Resick, Monson, \& Chard, 2007; Resick \& Schnicke, 1993), published content from peerreviewed journals (Angelo, Miller, \& Zoellner, 2008; Becker et al., 2009; Brady et al., 2000; Cochran, Pruitt, Fukuda, Zoellner, \& Feeny, 2008; Connor et al., 1999; Feeny, Zoellner, \& Kahana, 2009; Feeny, Zoellner, Mavissakalian, \& Roy-Byrne, 2009; Martenyi et al., 2002a; Martenyi et al., 2002b; McRae et al., 2004; Onder, Tural, \& Aker, 2006; Pruitt, Zoellner, Feeny, Caldwell, \& Hanson, 2012; Ravindran \& Stein, 2010; Roy-Byrne et al., 2003; Steckler \& Risbrough, 2012; Van der Kolk et al., 1994; Zoellner, Feeny, \& Bittinger, 2009), and consultation with expert psychologists and psychiatrists. Treatment descriptions were matched on content, style, length, reading level, grade level, sentences per paragraph, words per sentence, and characters per word (see Table 1 for relevant statistics). One-way ANOVAs showed no differences between therapy descriptions in terms of the number of sentences per paragraph $F(2$, $30)=0.07, p>.05$, the number of words per sentence $F(2,30)=0.59, p>.05$, and the number of characters per word $F(2,30)=0.04, p>.05$.

\section{Table 1}

Word Counts and Readability Statistics of Treatment Descriptions

\begin{tabular}{lccc}
\hline & $\begin{array}{c}\text { Exposure } \\
\text { Therapy }\end{array}$ & $\begin{array}{c}\text { Cognitive } \\
\text { Therapy }\end{array}$ & $\begin{array}{c}\text { Medication } \\
\text { Therapy }\end{array}$ \\
\hline Word Count & 279 & 295 & 342 \\
Reading Level & 38.9 & 41.0 & 36.4 \\
Grade Level & 12 & 12 & 12 \\
Sentences Per Paragraph & 1.3 & 1.3 & 1.4 \\
Words per Sentence & 20.9 & 22.0 & 24.0 \\
Characters per word & 5.0 & 5.2 & 5.1 \\
\hline
\end{tabular}


To assess participants' perceptions of treatment efficacy and personal attitudes concerning the treatment options, participants completed the Credibility Scale (CS; Addis \& Carpenter, 1999; see Appendix E) and Personal Reactions to the Rationales (PRR; Addis \& Carpenter, 1999; see Appendix F) scale after reading about each of the presented treatment options. The CS has 7 items (e.g., "How logical does this therapy seem to you?") and the PRR has 5 items (e.g., "If you had PTSD and went to see a therapist, how helpful do you think this therapy would be for you?") and both were found to be internally consistent and reliable by Addis and Carpenter (1999), with Cronbach's alphas ranging from 0.87-0.93 and 0.94-0.95, respectively. In the original study, the CS and the PRR were rated on a 7-point scale from 1 ("Not at all") to 7 ("Extremely"). In the present studies, both the CS and PRR were erroneously coded on 5-point Likert scales, also ranging from 1 ("Not at all") to 5 ("Extremely"). Both measures remained strongly internally consistent, with Cronbach's alphas ranging from 0.900.93 and $0.92-0.94$ respectively. The three treatment options were shown to each of the participants in random order to control for any order effects.

\section{Treatment Choice}

After assessment for symptoms of psychopathology, trauma exposure, and credibility and personal attitudes concerning the treatment choices, participants were asked, "If you had a choice between medication therapy, exposure therapy, cognitive therapy, or no therapy to help you with trauma-related symptoms (e.g., nightmares, avoiding situations that remind you of the trauma, feeling distant and cut off from people, and feeling watchful and on guard even when there is no need to be), which would you choose?" Participants were subsequently asked which treatment they would choose if their previous treatment choice failed; this question was asked repeatedly until the participant either chose 'No Treatment', or no other treatment choices remained. 


\section{Combination Therapy}

After the initial forced treatment choice questions, participants were asked, "Sometimes people are given the choice between individual psychotherapy, medication, or a combination of both. If you were given this choice, what would you pick?" The options they were given were: (1) only psychotherapy, (2) only medication therapy (3) simultaneous medication therapy and psychotherapy, (4) medication therapy, followed by psychotherapy if needed (5) psychotherapy, followed by medication therapy if needed, and (6) no therapy.

\section{Analyses}

Chi-square goodness of fit tests were used to assess: (1) individuals' treatment preferences between CPT, PE, pharmacotherapy and no treatment; and (2) individuals' preferences for combination of psychotherapy and medication therapy. To assess for differences in mean scores of treatment credibility, within subject, repeated measures ANOVAs were used, with total CS and PRR scores as dependent variables. All analyses were run using SPSS, version 19 (IBM Corp., 2010).

\section{Results}

\section{Study 1: Undergraduate Participant Characteristics}

Three $(3.2 \%)$ participants recruited from the undergraduate sample reported a prior diagnosis of PTSD by a licensed clinician. As assessed by the LEC, the undergraduate sample reported personally experiencing a wide variety of traumatic stressors (see Table 2). Physical assaults, other unwanted or uncomfortable sexual experiences, transportation accidents, and sexual assaults were the most frequently experienced traumatic stressors reported by participants 
Table 2

Study 1: Undergraduate Sample Trauma Exposure $(n=119)$

\begin{tabular}{|c|c|c|c|c|c|}
\hline & $\begin{array}{c}\text { Happened } \\
\text { Personally } \\
n(\%)\end{array}$ & $\begin{array}{c}\text { Witnessed } \\
\text { It } \\
n(\%)\end{array}$ & $\begin{array}{l}\text { Learned } \\
\text { About it } \\
n(\%)\end{array}$ & $\begin{array}{l}\text { Not Sure } \\
n(\%)\end{array}$ & $\begin{array}{c}\text { Does Not } \\
\text { Apply } \\
n(\%)\end{array}$ \\
\hline Natural disaster & $16(13.4)$ & $6(5)$ & $54(45.4)$ & $4(3.4)$ & $39(32.8)$ \\
\hline Fire or explosion & $5(4.2)$ & $14(11.8)$ & $51(42.9)$ & $9(7.6)$ & $40(33.6)$ \\
\hline Transportation accident & $39(32.8)$ & $23(19.3)$ & $37(31.1)$ & $2(1.7)$ & $18(15.1)$ \\
\hline Serious accident & $21(17.6)$ & $25(21)$ & $32(26.9)$ & $8(6.7)$ & $33(27.7)$ \\
\hline Exposure to toxic substance & $4(3.4)$ & $4(3.4)$ & $31(26.1)$ & $15(12.6)$ & $65(54.6)$ \\
\hline Physical assault & $34(28.6)$ & $23(19.3)$ & $27(22.7)$ & $9(7.6)$ & $26(21.8)$ \\
\hline Assault with a weapon & $10(8.4)$ & $13(10.9)$ & $38(31.9)$ & $3(2.5)$ & $55(46.2)$ \\
\hline Sexual assault & $8(6.7)$ & $1(0.8)$ & $43(36.1)$ & $5(4.2)$ & $62(52.1)$ \\
\hline $\begin{array}{l}\text { Other unwanted or } \\
\text { uncomfortable sexual experience }\end{array}$ & $32(26.9)$ & $4(3.4)$ & $26(21.8)$ & $5(4.2)$ & $52(43.7)$ \\
\hline $\begin{array}{l}\text { Combat or exposure to a war } \\
\text { zone }\end{array}$ & $1(0.8)$ & $2(1.7)$ & $38(31.9)$ & $2(1.7)$ & $76(63.9)$ \\
\hline Captivity & $1(0.8)$ & $2(1.7)$ & $26(21.8)$ & $5(4.2)$ & $85(71.4)$ \\
\hline Life-threatening illness or injury & $7(5.9)$ & $41(34.5)$ & $25(21)$ & $3(2.5)$ & $43(36.1)$ \\
\hline Severe human suffering & $3(2.5)$ & $23(19.3)$ & $31(26.1)$ & $13(10.9)$ & $49(41.2)$ \\
\hline Sudden, violent death & - & $12(10.1)$ & $40(33.6)$ & $7(5.9)$ & $60(50.4)$ \\
\hline $\begin{array}{l}\text { Sudden, unexpected death of } \\
\text { someone close to you }\end{array}$ & - & $48(40.3)$ & $23(19.3)$ & $7(5.9)$ & $41(34.5)$ \\
\hline $\begin{array}{l}\text { Serious injury, harm, or death } \\
\text { you caused to someone else }\end{array}$ & - & $11(9.2)$ & $7(5.9)$ & $7(5.9)$ & $94(79)$ \\
\hline $\begin{array}{l}\text { Another very stressful event or } \\
\text { experience }\end{array}$ & $42(35.3)$ & $21(17.6)$ & $14(11.8)$ & $16(13.4)$ & $26(21.8)$ \\
\hline
\end{tabular}




\section{Study 2: Online Participant Characteristics}

Ninety (96.8\%) participants recruited online reported a prior diagnosis of PTSD by a licensed clinician. As assessed by the LEC, the online sample reported personally experiencing a wide variety of traumatic stressors (see Table 3). Physical assaults, other unwanted or uncomfortable sexual experiences, transportation accidents, and sexual assaults were the most frequently experienced traumatic stressors reported by these participants. Compared with the undergraduate sample, participants recruited online reported higher scores for: (1) stress, anxiety, depression and PTSD (see Table 4). As the participants from the two studies differed significantly on rates of prior PTSD diagnosis and scores on measures of mental health symptoms, the samples were not combined for the purposes of hypothesis testing.

\section{Table 3}

Study 2: Online Sample Trauma Exposure $(n=126)$

\begin{tabular}{lccccc}
\hline & $\begin{array}{c}\text { Happened } \\
\text { Personally }\end{array}$ & $\begin{array}{c}\text { Witnessed } \\
\text { It }\end{array}$ & $\begin{array}{c}\text { Learned } \\
\text { About it }\end{array}$ & $\begin{array}{c}\text { Not Sure } \\
n(\%)\end{array}$ & $\begin{array}{c}\text { Does Not } \\
\text { Apply }\end{array}$ \\
& $40(31.7)$ & $18(14.3)$ & $19(15.1)$ & $1(0.8)$ & $48(38.1)$ \\
\hline Natural disaster & $35(27.8)$ & $17(13.5)$ & $14(11.1)$ & $3(2.4)$ & $57(45.2)$ \\
Fire or explosion & $65(51.6)$ & $11(8.7)$ & $19(15.1)$ & $2(1.6)$ & $29(23)$ \\
Transportation accident & $40(31.7)$ & $17(13.5)$ & $12(9.5)$ & $9(7.1)$ & $48(38.1)$ \\
Serious accident & $27(21.4)$ & $5(4)$ & $17(13.5)$ & $6(4.8)$ & $71(56.3)$ \\
Exposure to toxic substance & $91(72.2)$ & $11(8.7)$ & $8(6.3)$ & $0(0)$ & $16(12.7)$ \\
Physical assault & $46(36.5)$ & $13(10.3)$ & $17(13.5)$ & $5(4)$ & $45(35.7)$ \\
Assault with a weapon & $75(59.5)$ & $2(1.6)$ & $13(10.3)$ & $2(1.6)$ & $34(27)$ \\
Sexual assault & & & & &
\end{tabular}


Combat or exposure to a war

zone

Captivity

Life-threatening illness or injury

Severe human suffering

Sudden, violent death

Sudden, unexpected death of someone close to you

Serious injury, harm, or death you caused to someone else

Another very stressful event or experience

$\begin{array}{ccccc}24(19) & 4(3.2) & 23(18.3) & 1(0.8) & 74(58.7) \\ 27(21.4) & 3(2.4) & 14(11.1) & 7(5.6) & 75(59.5) \\ 41(32.5) & 19(15.1) & 12(9.5) & 1(0.8) & 53(42.1) \\ 37(29.4) & 28(22.2) & 13(10.3) & 10(7.9) & 38(30.2) \\ - & 32(25.4) & 34(27) & 5(4) & 55(43.7) \\ - & 57(45.2) & 21(16.7) & 2(1.6) & 46(36.5) \\ - & 23(18.3) & 7(5.6) & 7(5.6) & 89(70.6) \\ 80(63.5) & 12(9.5) & 5(4) & 9(7.1) & 20(15.9)\end{array}$

Table 4

Mental Health Symptomatology By Recruitment Source

\begin{tabular}{lcccc}
\hline Variable & $M$ & SD & $t$ & $p$ \\
\hline DASS-Stress & & & & \\
Study 1: Undergraduate & 7.98 & 5.30 & 7.67 & $<.001$ \\
Study 2: Online & 13.29 & 5.51 & & \\
DASS-Anxiety & & & & \\
Study 1: Undergraduate & 5.39 & 4.70 & 7.52 & $<.001$ \\
Study 2: Online & 10.45 & 5.73 & & \\
DASS-Depression & & & & \\
Study 1: Undergraduate & 6.57 & 5.84 & 6.89 & \\
Study 2: Online & 11.90 & 6.25 & &
\end{tabular}


Study 1: Undergraduate

Study 2: Online
15.92

$10.16<.001$

18.0

\section{Study 1: Undergraduate Sample Treatment Preferences and Credibility Ratings}

CT was preferred significantly more by undergraduate participants when compared with the other treatment options, $\chi^{2}(3, N=119)=41.32, p<.001$. As predicted, CT was the first choice for undergraduate participants, followed by ET as the second choice and MT as the third choice; 57 (47.9\%) chose CT, 34 (28.6\%) chose ET, $18(15.1 \%)$ chose MT, and $10(8.4 \%)$ chose no therapy (see Figure 1).

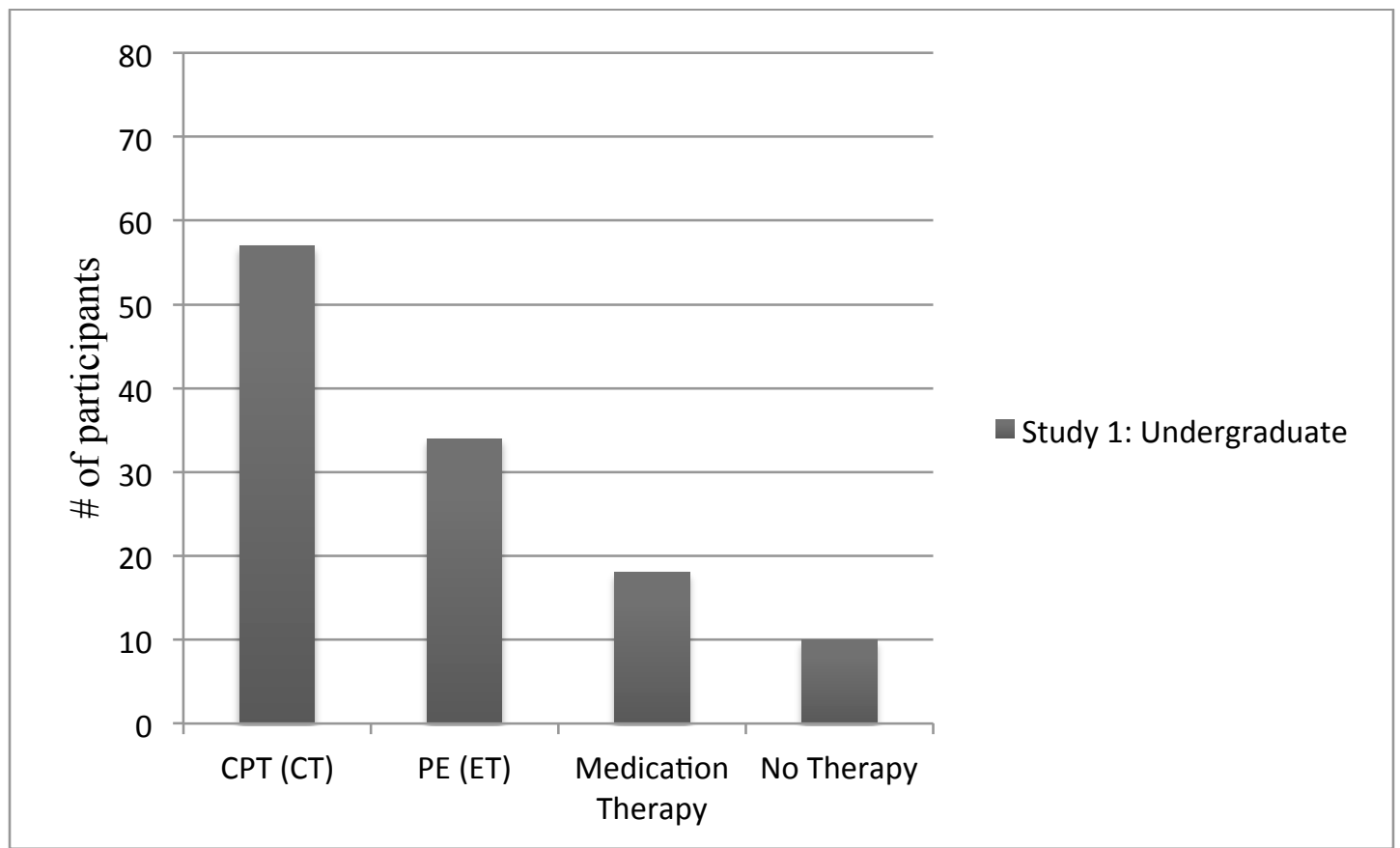

Figure 1. Study 1: Undergraduate sample treatment preference.

Undergraduate participants also significantly preferred psychotherapy alone when compared with combined psychotherapy and medication treatment options, $\chi^{2}(5, N=119)=$ 109.45, $p<.001$. As predicted, psychotherapy alone was the first choice $(N=56,47.0 \%)$. However, psychotherapy followed by medication therapy was the second choice $(N=34$, 
$28.6 \%)$, no treatment was the third choice $(N=10,8.4 \%)$, simultaneous psychotherapy and medication therapy was the fourth choice $(N=9,7.6 \%)$, medication followed by psychotherapy was the fifth choice $(N=7,5.9 \%)$, and medication alone was the last choice $(N=3,2.5 \%)$. Participants choosing only psychotherapy as their first choice was consistent with hypothesis 2 , but participants picked simultaneous psychotherapy and medication therapy as their fourth choice, which is contrary to the prediction made in hypothesis 2 .

There were significant differences in the undergraduate participants' ratings of the treatment rationales, $F(1.72,203.13)=19.14, p<.001$; CT was rated as the most credible treatment option $(M=24.25, \mathrm{SD}=5.23)$, followed by $\mathrm{ET}(M=22.77, \mathrm{SD}=5.48)$ and $\mathrm{MT}(M=$ $20.48, \mathrm{SD}=5.44)$. Helmert contrasts reveled that $\mathrm{CT}$ was rated as significantly more credible than ET and MT, $F(1,118)=28.18, p<.001$, and ET was rated as significantly more credible than MT, $F(1,118)=12.27, p=.001$. Undergraduate participants' personal reactions to the treatment rationales also differed significantly, $F(1.75,206.89)=43.71, p<.001$; undergraduate participants reacted most positively to $\mathrm{CT}(M=17.91, \mathrm{SD}=4.27)$, followed by $\mathrm{ET}(M=16.75$, $\mathrm{SD}=4.73)$ and $\mathrm{MT}(M=12.91, \mathrm{SD}=4.73)$. Helmert contrasts revealed undergraduate participants had significantly more positive reactions to CT than ET and MT, $F(1,118)=53.50$, $p<.001$, and reacted more positively to ET than MT, $F(1,118)=37.78, p<.001$.

\section{Study 2: Online Sample Treatment Preferences and Credibility Ratings}

CT was preferred significantly more by online participants when compared with the other treatment options, $\chi^{2}(3, N=126)=91.59, p<.001$. Unexpectedly, CT was the first choice for online participants, followed by MT as the second choice and ET as the third choice; 75 (59.5\%) chose CT, 28 (22.2\%) chose MT, 21 (16.7\%) chose ET, and 2 (1.6\%) chose no therapy (see Figure 2). Although it was expected that CT would be the first choice, it was unexpected that 
participants would be more likely to pick MT that ET. Online participants also significantly preferred psychotherapy alone when compared with combined psychotherapy and medication treatment options, $\chi^{2}(5, N=119)=109.45, p<.001$. As predicted, psychotherapy alone was the first choice $(N=47,37.3 \%)$, simultaneous psychotherapy and medication therapy was the second choice $(N=35,27.8 \%)$, psychotherapy followed by medication therapy was the third choice $(N$ $=29,23.0 \%)$, medication therapy followed by psychotherapy was the fourth choice $(N=10$, $7.9 \%)$, medication followed by psychotherapy was the fifth choice $(N=3,2.4 \%)$, and medication alone was the last choice $(N=2,1.6 \%)$.

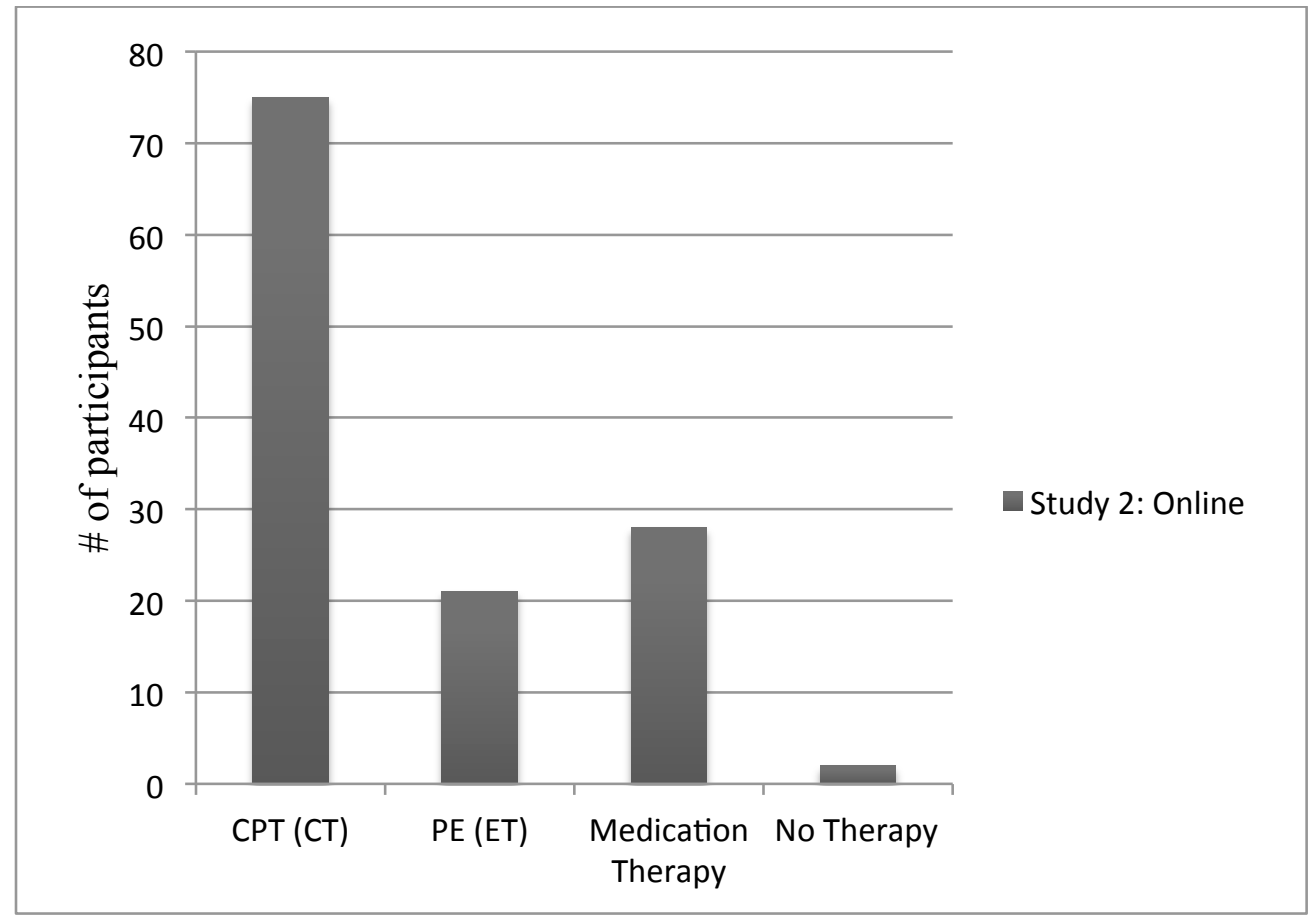

Figure 2. Study 2: Online sample treatment preference.

There were significant differences in the online participants' ratings of the treatment rationales, $F(2,250)=20.07, p<.001$. CT was rated as the most credible treatment option $(M=$ $25.50, \mathrm{SD}=6.31)$, followed by MT $(M=21.46, \mathrm{SD}=6.69)$ and $\mathrm{ET}(M=21.08, \mathrm{SD}=7.36)$. Helmert contrasts reveled that $\mathrm{CT}$ was rated as significantly more credible than ET and MT, $F$ 
$(1,125)=41.79, p<.001$, but ET was not rated as significantly more credible than MT, $F(1$, $125)=0.23, p=.631$. Online participants' personal reactions to the treatment rationales also differed significantly, $F(2,250)=32.34, p<.001$. Online participants reacted most positively to $\mathrm{CT}(M=18.23, \mathrm{SD}=5.28)$, followed by ET $(M=14.79, \mathrm{SD}=5.99)$ and $\mathrm{MT}(M=13.12, \mathrm{SD}=$

5.62). Helmert contrasts revealed online participants had significantly more positive reactions to CT than ET and MT, $F(1,125)=67.76, p<.001$, and reacted more positively to ET than MT, $F$ $(1,125)=5.78, p=.018$.

\section{Discussion}

The present research aimed to determine (1) what types of treatments individuals would choose if they envisioned themselves in need of treatment for the symptoms of PTSD and (2) how effective and credible they would find the available empirically-validated treatment options. Since all previous studies in this area have included undergraduate or collegiate students, participants in Study 2 were exclusively recruited online-all from groups or forums where participants sought to discuss or gain support for mental health symptoms, which provided a more heterogeneous sample with regard to trauma exposure. In both studies, participants were presented with a general description of medication therapy for the treatment of PTSD symptoms, rather than sertraline alone. Advancing previous research, this study provided participants with the description of a treatment option that more accurately resembles how pharmacotherapy would be offered to patients in clinical settings. The two present studies were the first in which individuals were asked to choose between descriptions of the three treatments for PTSD with the strongest empirical support (i.e., CPT, PE, and pharmacotherapy).

Consistent with hypotheses, participants in both studies chose CPT (presented as 'cognitive therapy') as their first choice for treatment. In Study 1, undergraduate participants 
chose PE (presented as 'exposure therapy') as their second choice and medication therapy as their third choice. However, contrary to prediction, the pattern was opposite in Study 2, and online participants (who had higher scores on questionnaires measuring symptoms of depression, anxiety, stress, and PTSD than those in Study 1) chose medication therapy as their second choice, followed by PE as their third choice. Interestingly, in Becker and colleagues' (2009) study on PTSD treatment preference in a law enforcement sample, the same pattern was seen in a subsample of the study who met criteria for PTSD (as assessed by the Posttraumatic Stress Diagnostic Scale (PDS); Foa, Cashman, Jaycox, \& Perry, 1997); in that study, those whose symptoms met criteria for PTSD also chose PE as their third choice, opting for psychodynamic therapy as their second choice. In their study, the overall sample chose exposure and medication therapies as their second and third choices respectively, but participants who met criteria for PTSD, chose psychodynamic therapy as their second choice and exposure therapy became the third most frequently selected choice (Becker and colleagues did not include medication therapy as a treatment option).

One possible explanation for this pattern of findings in the online sample could be that these participants considered medication therapy to be a quicker solution, particularly those participants who have higher symptom severity scores including symptoms of depression. However, in prior research conducted by Becker and colleagues (2009), participants chose psychodynamic therapy as their second choice, an option that would take longer to resolve symptoms than exposure therapy. As such, it seems unlikely that wanting a quick fix is the explanation for a drop in preference for PE in more symptomatic samples. Alternatively, as avoidance of trauma-related cues is a key symptom of PTSD, a possible reason for the pattern of findings in Study 2 is that individuals with higher PTSD-related avoidance chose exposure-based 
therapies less often than non-avoidant individuals. Exposure therapies require that patients repeatedly imagine themselves re-experiencing their trauma for a prolonged period of time during which they recount the worst traumatic experience out loud and in the present tense as if they were happening right now, listen to digital recordings of their sessions between sessions, and systematically expose themselves to anxiety-provoking stimuli that are reminiscent or symbolic of their traumatic experience. Individuals who suffer from more of the avoidancerelated symptoms of PTSD might find the idea of engaging in exposure techniques to be noxious and/or extremely anxiety provoking. As a result, they may be less inclined to select a treatment that would challenge their maladaptive coping strategy of avoiding their trauma.

As hypothesized, participants in Study 1 found CT to be more credible than ET and medication therapy, and ET to be more credible than MT. However, although participants in Study 2 also found CT to be more credible than ET, they found ET and MT to be equally credible options. In Becker and colleagues' (2009) study, ET was rated as the most credible treatment option, unlike in the present studies, where CT is rated highest. Several factors could be serving to moderate participants' perceptions of treatment credibility, such as symptom severity, prior exposure to traumatic events, previous treatment experience, the wording and style of treatment descriptions, and even differences in demographics. More participants in Study 2 self-reported a prior diagnosis of PTSD, a prior history of treatment for PTSD symptoms, and higher scores on measures of psychopathology.

Not only do these differences suggest higher levels of distress and impairment in these individuals' lives, they highlight the likelihood that participants in Study 2 are also more likely to have had higher levels of contact with health care providers for their mental health problems. Health care providers consistently underutilize exposure-based therapies—-both for PTSD 
(Becker, Zayfert, \&Anderson, 2004; Foy, Kagan, McDermott, Leskin, Sipprelle, \& Paz, 1996; Rosen et al., 2004) and other anxiety disorders (Freiheit, Vye, Swan, \& Cady, 2004) — and this underutilization stems from a variety of reasons, including lack of training, perceptions of suitability or patients' ability to handle such treatment, time constraints, and clinician personal preference and/or psychotherapeutic orientation (Becker, Darius, \& Schaumberg, 2007).

Mental health care providers with negative perceptions of, or lack of training in, exposure practices may serve to validate patients' anxieties or perceptions of credibility about such treatment options and cause them to reject the use of an efficacious treatment, such as PE. Given the dearth of clinicians trained in the delivery of evidence-based therapies such as CPT and PE, it is not best patient-centered practice for clinicians to allow prejudice or discomfort with these protocols to stand in the way of motivating clients to engage in these treatments. Therapists' inaccurate perceptions of treatment efficacy must be addressed through training and the development of standardized treatment descriptions based on research findings. Empirical research findings show overwhelming support for the use of TFCBTs in the treatment of PTSD symptoms, and clinical practice should be guided by these efficacy findings (rather than clinician's subjective biases) in order to provide good patient-centered care. The results of these studies clearly show that individuals have strong preferences for psychotherapy over pharmacotherapy and cognitive therapy over other effective treatments for PTSD. Given these findings, health care providers should carefully consider the potentially detrimental impact that not matching individuals to their treatment of choice may have on symptom reduction, dropout rates, therapeutic alliance, motivation and engagement in therapy, homework completion, treatment satisfaction ratings during and after treatment, and/or improvements in health related quality of life. 


\section{Limitations}

It was not possible to access a representative sample of treatment-seeking individuals in North America who met diagnostic criteria for PTSD. Demographic characteristics varied between the two studies (e.g., participants in Study 2 were older and more were female than those in Study 1), and neither of the studies were recruited to be representative of a national sample. Clinical settings that offer treatment specifically for PTSD symptoms are scarce in Toronto, and none are publicly funded through the Ontario Health Insurance Plan. With the exception of certain special populations, such as military veterans whose treatment is paid for by Veterans Affairs Canada, or military personal whose treatment is paid for through benefit entitlement with the Department of National Defense, people who present themselves to their physicians seeking treatment for PTSD are referred to private counselors. However, those who seek treatment in private clinics are still not representative of the PTSD treatment-seeking population, which includes those who cannot afford to pay for private services, those who do not live in urban centers with trained psychotherapists, those who are transient and therefore cannot remain in one place long enough to complete a course of treatment, those with physical disabilities (such as deafness) and those with comorbid mental health problems (such as developmental delay or autism spectrum disorder).

To overcome this limitation, participants were recruited over the Internet in Study 2, where geographical and socio-economic barriers are reduced. The population of North America is ethnically diverse, and not all its residents are English-speaking. Participants who did not selfreport being fluent readers and writers of the English language were excluded. Other underrepresented populations included poor, homeless or isolated individuals without access to 
the Internet, and those with Internet access who are unfamiliar with Internet support or discussion groups.

Methodologically, the PDS and the PCL questionnaires are the most empirically validated self-report measures for the assessment of PTSD symptoms, particularly in terms of test-retest reliability, internal consistency, convergent and discriminant validity, and diagnostic utility (Adkins, Weathers, McDevitt-Murphy, \& Daniels, 2008). The PDS has 49 items and requires 10-15 minutes to complete. While the PDS, unlike the PCL, is one of the few measures to assess for the A2 criterion for PTSD, the entire survey was 20-30 minutes long, and adding the PDS would have made the survey longer than 30 minutes in total. Given limitations in my ability to ethically incentivize participants, the fact that the PCL-S is available in the public domain, and a short amount of time available for recruitment, the LEC and the PCLS were used to gauge PTSD symptom severity instead of the PDS. As symptom severity was not included as a moderator variable in analyses, this decision had a minimal impact on the results of this research.

\section{Research Implications}

Currently, there is no published data that demonstrates whether clients matched to their treatment of choice have more significant reductions in PTSD and comorbid symptom severity, lower dropout rates, better therapeutic alliance, better motivation and engagement in therapy, higher levels of homework completion, higher treatment satisfaction ratings during and after treatment, and/or improvements in health related quality of life. Moreover, there has been no research on the impact of clinician descriptions of treatments on subsequent patient treatment preferences. Although CPT, PE and MT are the treatments with strongest research support, we know little about the moderators of treatment success. Since participants in both studies strongly preferred CPT as their first choice, clinical researchers conducting effectiveness and efficacy 
studies for the treatment of PTSD symptoms using evidence-based therapies should consider conducting a randomized control trial in which participants are asked for their treatment preference and subsequently randomized to treatment, allowing researchers to study whether being matched to their treatment of choice results in significant differences in treatment outcome.

Given the differences in treatment preference and credibility scores between Study 1 and Study 2, it is important to consider the impact that individual differences in demographics and symptom severity have on patient preference. As have been demonstrated, CPT and PE are consistently shown to be the first and second most frequently chosen treatment options in undergraduate, law enforcement, and online samples. Thus, further exploration of treatment preference differences in non-English-speaking, ethnically diverse, and marginalized populations is a necessary next step in the dissemination of evidence-based practice for the treatment of PTSD symptoms. Also, in the absence of standardized descriptions of evidence-based PTSD treatments, such research will continue to suffer from deficiencies in face and external validity; in clinical settings, treatment descriptions are not delivered verbatim from a set script that is based entirely on research findings. As such, preference studies must account for expected variations in treatment descriptions that can occur from clinician to clinician and take into account how these changes can affect patients' preferences and choices. As there is a need to understand the requirements and desires of difference populations in terms of their treatment preferences, so too is there a need to understand how the changes in presentation of treatment options can affect engagement, treatment commencement and drop-out rates, and therapeutic alliance. 


\section{Clinical Implications}

In the absence of definitive empirical findings on the impact that clinician descriptions have on patient preferences for treatment, and the advantages and disadvantages of matching individuals to their treatment of choice, clinicians should endeavor to match treatment-seeking individuals to the treatment they prefer, while attempting to present an unbiased description of the available evidence-based treatments. One example of why it is important to provide accurate information to clients and to match them to their treatments of choice comes for the depression treatment literature. In the patient preference and treatment efficacy research literature for depression symptoms, research shows that remission rates were impressive for both counseling and antidepressant therapies, but symptom severity decreased faster with antidepressant medication (Chilvers et al., 2001). However, Chilvers and colleagues had significant difficulty recruiting participants into the randomization arm (where participants would not be allowed to select their treatment of choice), a large majority of whom preferred counseling. Additionally, a systematic review of patient preferences for treatment of major depressive disorder showed that, while patient preferences had little impact on depression severity outcomes in controlled trials, they have a significant impact on other outcomes such as entry into treatment and the development of clinician/patient alliance (Gelhorn, Sexton, \& Classi, 2011). If, as with those seeking treatment for symptoms of depression, those seeking treatment for PTSD symptoms are unwilling to engage in treatments they perceive as unpalatable or ineffective, it is likely best to offer as many evidence-based treatments as possible and allow patients to make the choices that match their preferences. The abovementioned findings show that while some treatments might be more effective for symptom reduction and might even be more cost effective in the short or medium term, clinicians and patients might be best served by honoring individual choice, as free 
from therapist bias as possible, as a strategy to motivate individuals to initiate and remain in therapy, develop better therapeutic alliances, and affect positive changes on other health outcomes.

Individual preference for treatment modality is a factor worthy of serious consideration, particularly if individuals differ sharply in their preferences and if these preferences moderate the efficacy of these treatments and/or moderate individuals' willingness to avail themselves of these resources. The present research reveals that individuals generally prefer psychotherapeutic treatment options to pharmacotherapy and populations with higher scores on measures of psychopathology differ in their choices for treatment from those with lower scores. Research and clinical practice must continue to take into account all factors that could moderate treatment commencement, engagement, compliance, and efficacy, and individual preference for treatment is certainly one such important factor. 


\section{References}

Addis, M. E., \& Carpenter, K. M. (1999). Why, why, why?: Reason-giving and rumination as predictors of response in activation-and insight-oriented treatment rationales. Journal of Clinical Psychology, 55(7), 881-894.

Adkins, J. W., Weathers, F. W., McDevitt-Murphy, M., \& Daniels, J. B. (2008). Psychometric properties of seven self-report measures of posttraumatic stress disorder in college students with mixed civilian trauma exposure. Journal of Anxiety Disorders, 22(8), 13931402.

American Psychiatric Association. (1980). Diagnostic and statistical manual of mental disorders (3rd ed.). Washington, DC: Author.

American Psychiatric Association. (1987). Diagnostic and statistical manual of mental disorders (3rd ed., rev.). Washington, DC: Author.

American Psychiatric Association. (2000). Diagnostic and statistical manual of mental disorders (4th ed., text rev.). Washington, DC: Author.

Angelo, F. N., Miller, H. E., Zoellner, L. A., \& Feeny, N. C. (2008). "I Need to Talk About It": A Qualitative Analysis of Trauma-Exposed Women's Reasons for Treatment Choice. Behavior Therapy, 39(1), 13.

Antony, M. M., Bieling, P. J., Cox, B. J., Enns, M. W., \& Swinson, R. P. (1998). Psychometric properties of the 42-item and 21-item versions of the Depression Anxiety Stress Scales in clinical groups and a community sample. Psychological Assessment, 10(2), 176.

Becker, C. B., Darius, E., \& Schaumberg, K. (2007). An analog study of patient preferences for exposure versus alternative treatments for posttraumatic stress disorder. Behaviour Research and Therapy, 45(12), 2861-2873. 
Becker, C. B., Meyer, G., Price, J. S., Graham, M. M., Arsena, A., Armstrong, D. A., \& Ramon, E. (2009). Law enforcement preferences for PTSD treatment and crisis management alternatives. Behaviour Research and Therapy, 47(3), 245-253.

Becker, C. B., Zayfert, C., \& Anderson, E. (2004). A survey of psychologists' attitudes towards and utilization of exposure therapy for PTSD. Behaviour Research and Therapy, 42(3), 277-292.

Benedek, D. M., Friedman, M. J., Zatzick, D., \& Ursano, R. J. (2009). Guideline watch (March 2009): Practice guideline for the treatment of patients with acute stress disorder and posttraumatic stress disorder. FOCUS: The Journal of Lifelong Learning in Psychiatry, 7(2), 204-213.

Benish, S. G., Imel, Z. E., \& Wampold, B. E. (2008). The relative efficacy of bona fide psychotherapies for treating post-traumatic stress disorder: a meta-analysis of direct comparisons. Clinical Psychology Review, 28(5), 746-758.

Bisson, J., \& Andrew, M. (2007). Psychological Treatment of Post-traumatic Stress Disorder (PTSD)(Review). Wiley.

Bisson, J., Ehlers, A., Matthews, R., Pilling, S., Richards, D., \& Turner, S. (2007). Systematic review and metaanalysis of psychological treatments for posttraumatic stress disorder. British Journal Of Psychiatry, 190, 97-104.

Blanchard, E. B., Jones-Alexander, J., Buckley, T. C., \& Forneris, C. A. (1996). Psychometric properties of the PTSD Checklist (PCL). Behaviour Research and Therapy, 34(8), 669673.

Bradley, R., Greene, J., Russ, E., Dutra, L., \& Westen, D. (2005). A multidimensional metaanalysis of psychotherapy for PTSD. American Journal of Psychiatry, 162(2), 214-227. 
Brady, K., Pearlstein, T., Asnis, G. M., Baker, D., Rothbaum, B., Sikes, C. R., \& Farfel, G. M. (2000). Efficacy and safety of sertraline treatment of posttraumatic stress disorder. JAMA: The Journal of the American Medical Association, 283(14), 1837-1844.

Breslau, N., Davis, G. C., Andreski, P., \& Peterson, E. (1991). Traumatic events and posttraumatic stress disorder in an urban population of young adults. Archives of General Psychiatry, 48(3), 216.

Breslau, N., Kessler, R. C., Chilcoat, H. D., Schultz, L. R., Davis, G. C., \& Andreski, P. (1998). Trauma and posttraumatic stress disorder in the community: the 1996 Detroit Area Survey of Trauma. Archives of General Psychiatry, 55(7), 626.

Breslau, N., Wilcox, H. C., Storr, C. L., Lucia, V. C., \& Anthony, J. C. (2004). Trauma exposure and posttraumatic stress disorder: A study of youths in urban America. Journal of Urban Health, 81, 530-544.

Chard, K. M. (2005). An evaluation of cognitive processing therapy for the treatment of posttraumatic stress disorder related to childhood sexual abuse. Journal of Consulting and Clinical Psychology, 73(5), 965.

Chilvers, C., Dewey, M., Fielding, K., Gretton, V., Miller, P., Palmer, B., ... \& Harrison, G. (2001). Antidepressant drugs and generic counselling for treatment of major depression in primary care: Randomised trial with patient preference arms. BMJ, 322(7289), 772.

Cloitre, M. (2009). Effective psychotherapies for posttraumatic stress disorder: A review and critique. CNS Spectrums, 14(1), 32-43.

Cochran, B. N., Pruitt, L., Fukuda, S., Zoellner, L. A., \& Feeny, N. C. (2008). Reasons Underlying Treatment Preference An Exploratory Study. Journal of Interpersonal Violence, 23(2), 276-291. 
Connor, K. M., Sutherland, S. M., Tupler, L. A., Churchill, L. E., Malik, M. L., \& Davidson, J. R. T. (1999). Fluoxetine in posttraumatic stress disorder: A randomized, placebocontrolled trial. British Journal of Psychiatry, 175, 17-22.

Davidson, J., Baldwin, D., Stein, D. J., Kuper, E., Benattia, I., Ahmed, S., ... \& Musgnung, J. (2006). Treatment of posttraumatic stress disorder with venlafaxine extended release: a 6month randomized controlled trial. Archives of General Psychiatry, 63(10), 1158.

Davidson, J. R. T., Hughes, D., Blazer, D. G., \& George, L. K. (1991). Posttraumatic stress disorder in the community: An epidemiological study. Psychological Medicine, 21(3), $713-721$.

Davidson, J., Kudler, H., Smith, R., Mahorney, S. L., Lipper, S., Hammett, E., ... \& Cavenar Jr, J. O. (1990). Treatment of posttraumatic stress disorder with amitriptyline and placebo. Archives of General Psychiatry, 47(3), 259.

Davidson, J., Rothbaum, B. O., Tucker, P., Asnis, G., Benattia, I., \& Musgnung, J. J. (2006). Venlafaxine extended release in posttraumatic stress disorder: a sertraline-and placebocontrolled study. Journal of Clinical Psychopharmacology, 26(3), 259.

Davidson, J., Swartz, M., \& Stork, M. (1985). A diagnostic and family study of PTSD. American Journal of Psychiatry, 142, 90-93.

Ehlers, A., Bisson, J., Clark, D. M., Creamer, M., Pilling, S., Richards, D., ... \& Yule, W. (2010). Do all psychological treatments really work the same in posttraumatic stress disorder?. Clinical Psychology Review, 30(2), 269.

Dobry, Y., \& Sher, L. (2012). Post-traumatic stress disorder, associated medical illnesses, and suicidal behavior: Plenty of room for new research. Australian and New Zealand Journal of Psychiatry, 46(7), 684. 
Engdahl, B., Dikel, T. N., Eberly, R., \& Blank, A. (1998). Comorbidity and course of psychiatric disorders in a community sample of former prisoners of war. American Journal of Psychiatry, 155(12), 1740-1745.

Feeny, N. C., Zoellner, L. A., \& Kahana, S. Y. (2009). Providing a treatment rationale for PTSD: Does what we say matter? Behaviour Research and Therapy, 47(9), 752-760.

Feeny, N. C., Zoellner, L. A., Mavissakalian, M. R., \& Roy-Byrne, P. P. (2009). What would you choose? sertraline or prolonged exposure in community and PTSD treatment seeking women. Depression and Anxiety, 26(8), 724-731.

Ferrada-Noli, M., Asberg, M., Ormstad, K., Lundin, T., \& Sundbom, E. (1998). Suicidal behavior after severe trauma. Part 1: PTSD diagnoses, psychiatric comorbidity, and assessments of suicidal behavior. Journal of Traumatic Stress, 11(1), 103-112.

Foa, E. B., Cashman, L., Jaycox, L., \& Perry, K. (1997). The validation of a self-report measure of posttraumatic stress disorder: the Posttraumatic Diagnostic Scale. Psychological Assessment, 9(4), 445.

Foa, E. B., Dancu, C. V., Hembree, E. A., Jaycox, L. H., Meadows, E. A., \& Street, G. P. (1999). A comparison of exposure therapy, stress innoculation training, and their combination for reducing posttraumatic stress disorder in female assault victims. Journal of Consulting and Clinical Psychology, 67(2), 194-200.

Foa, E., Hembree, E., \& Rothbaum, B. O. (2007). Prolonged exposure therapy for PTSD: Emotional processing of traumatic experiences therapist guide. Oxford University Press.

Foa, E. B., Huppert, J. D., \& Cahill, S. P. (2006). Emotional processing theory: An update. In B. O. Rothbaum (Ed.), Pathological anxiety: Emotional processing in etiology and treatment (pp. 3-24). New York, NY: Guilford Press. 
Foa, E. B. \& Kozak, M. J. (1986). Emotional processing of fear: Exposure to corrective information. Psychological Bulletin, 99, 20-35.

Foa, E. B., \& McNally, R. J. (1996). Mechanisms of change in exposure therapy. In R. M. Rapee (Ed.), Current controversies in the anxiety disorders (pp. 329-343). Guilford Press.

Foa, E. B., Rothbaum, B. O., Riggs, D. S., \& Murdock, T. B. (1991). Treatment of posttraumatic stress disorder in rape victims: a comparison between cognitive-behavioral procedures and counseling. Journal of Consulting and Clinical Psychology, 59(5), 715.

Foy, D. W., Kagan, B., McDermott, C., Leskin, G., Sipprelle, R. C., \& Paz, G. (1996). Practical parameters in the use of flooding for treating chronic PTSD. Clinical Psychology and Psychotherapy, 3(3), 169-175.

Frank, J. B., Kosten, T. R., Giller, E. L., \& Dan, E. (1988). A randomized clinical trial of phenelzine and imipramine for posttraumatic stress disorder. The American Journal of Psychiatry, 145(10), 1289-1291.

Freiheit, S. R., Vye, C., Swan, R., \& Cady, M. (2004). Cognitive-behavioral therapy for anxiety: Is dissemination working? The Behavior Therapist, 27(2), 25-32.

Galatzer-Levy, I. R., Nickerson, A., Litz, B. T., \& Marmar, C. R. (2012). Patterns of lifetime PTSD comorbidity: A latent class analysis. Depression and anxiety, 30(5), 489-496.

Gelhorn, H. L., Sexton, C. C., \& Classi, P. M. (2011). Patient preferences for treatment of major depressive disorder and the impact on health outcomes: A systematic review. The primary care companion to CNS disorders, 13(5).

Gray, M. J., Litz, B. T., Hsu, J. L., \& Lombardo, T. W. (2004). Psychometric properties of the life events checklist. Assessment, 11(4), 330-341. 
Green, B. L., Lindy, J. D., Grace, M. C., \& Gleser, G. C. (1989). Multiple diagnosis in posttraumatic stress disorder: The role of war stressors. The Journal of Nervous and Mental Disease, 177(6), 329-335.

Greenberg, P. E., Sisitsky, T., Kessler, R. C., Finkelstein, S. N., Berndt, E. R., Davidson, J. R., ... \& Fyer, A. J. (1999). The economic burden of anxiety disorders in the 1990s. Journal of Clinical Psychiatry, 60(7), 427-435.

Helzer, J. E., Robins, L. N., \& McEvoy, L. (1987). Posttraumatic Stress Disorder in the general population: Findings of the epidemiological catchment area survey. The New England Journal of Medicine, 317(26), 1630-1634.

Henry, J. D., \& Crawford, J. R. (2005). The short-form version of the Depression Anxiety Stress Scales (DASS-21): Construct validity and normative data in a large non-clinical sample. British Journal of Clinical Psychology, 44(2), 227-239.

IBM Corp. (2010). IBM SPSS Statistics for Windows (Version 19.0). Armonk, NY: IBM Corp.

Kessler, R. C. (2000). Posttraumatic stress disorder: the burden to the individual and to society. Journal of Clinical Psychiatry, 61, 4-14.

Kessler, R. C., Berglund, P., Demler, O., Jin, R., Merikangas, K. R., \& Walters, E. E. (2005). Lifetime prevalence and age-of-onset distributions of DSM-IV disorders in the National Comorbidity Survey Replication. Archives of General Psychiatry, 62(6), 593.

Kessler, R. C., Chiu, W. T., Demler, O., \& Walters, E. E. (2005). Prevalence, severity, and comorbidity of 12-month DSM-IV disorders in the National Comorbidity Survey Replication. Archives of General Psychiatry, 62(6), 617. 
Kessler, R., Sonnega, A., Bromet, E., Hughes, M., \& Nelson, C. (1995). Posttraumatic Stress Disorder in the National Comorbidity Study. Archives of General Psychiatry, 52(12), 1048-1060.

Kilpatrick, D. G., \& Resnick, H. S. (1993). PTSD associated with exposure to criminal victimization in clinical and community populations. In J. R. T. Davidson \& E. B. Foa (Eds.), PTSD in review: Recent research and future directions (pp. 113-143).

Washington, DC: American Psychiatric Press.

Kotler, M., Iancu, I., Efroni, R., \& Amir, M. (2001). Anger, impulsivity, social support, and suicide risk in patients with posttraumatic stress disorder. The Journal of Nervous and Mental Disease, 189(3), 162-167.

Martenyi, F., Brown, E. B., Zhang, H., Koke, S. C., \& Prakash, A. (2002a). Fluoxetine v. placebo in prevention of relapse in post-traumatic stress disorder. The British Journal of Psychiatry, 181(4), 315-320.

Martenyi, F., Brown, E. B., Zhang, H., Prakash, A., \& Koke, S. C. (2002b). Fluoxetine versus placebo in posttraumatic stress disorder. The Journal of Clinical Psychiatry, 63(3), 199.

McRae, A. L., Brady, K. T., Mellman, T. A., Sonne, S. C., Killeen, T. K., Timmerman, M. A., \& Bayles-Dazet, W. (2004). Comparison of nefazodone and sertraline for the treatment of posttraumatic stress disorder. Depression and Anxiety, 19(3), 190-196.

Monson, C. M., Schnurr, P. P., Resick, P. A., Friedman, M. J., Young-Xu, Y., \& Stevens, S. P. (2006). Cognitive processing therapy for veterans with military-related posttraumatic stress disorder. Journal of Consulting and Clinical Psychology, 74(5), 898.

Onder, E., Tural, U., \& Aker, T. (2006). A comparative study of fluoxetine, moclobemide, and tianeptine in the treatment of posttraumatic stress disorder following an 
earthquake. European Psychiatry: The Journal of the Association of European Psychiatrists, 21(3), 174.

Oquendo, M. A., Halberstam, B., \& Mann, J. J. (2003). Risk factors for suicidal behavior. Standardized Evaluation in Clinical Practice, 22, 103-129.

Powers, M. B., Halpern, J. M., Ferenschak, M. P., Gillihan, S. J., \& Foa, E. B. (2010). A metaanalytic review of prolonged exposure for posttraumatic stress disorder. Clinical Psychology Review, 30(6), 635-641.

Pruitt, L. D., Zoellner, L. A., Feeny, N. C., Caldwell, D., \& Hanson, R. (2012). The effects of positive patient testimonials on PTSD treatment choice. Behaviour Research and Therapy, 50(12), 805-813.

Qureshi, S. U., Pyne, J. M., Magruder, K. M., Schulz, P. E., \& Kunik, M. E. (2009). The link between post-traumatic stress disorder and physical comorbidities: a systematic review. Psychiatric Quarterly, 80(2), 87-97.

Ravindran, L. N., \& Stein, M. B. (2010). Pharmacotherapy of post-traumatic stress disorder of post-traumatic stress disorder. In M. B. Stein \& T. Steckler (Eds.), Behavioural neurobiology of anxiety and its treatment (pp. 505-525). Heidelberg: Springer.

Resick, P. A., Monson, C. M., Chard, K. M. (2007). Cognitive processing therapy: Veteran/military version. Washington, DC: Department of Veterans’ Affairs.

Resick, P. A., Nishith, P., Weaver, T. L., Astin, M. C., \& Feuer, C. A. (2002). A comparison of cognitive-processing therapy with prolonged exposure and a waiting condition for the treatment for chronic posttraumatic stress disorder in female rape victims. Journal of Consulting and Clinical Psychology, 70(4), 867-879. 
Resick, P. A., Uhlmansiek, M. O. B., Clum, G. A., Galovski, T. E., Scher, C. D., \& Young-Xu, Y. (2008). A randomized clinical trial to dismantle components of cognitive processing therapy for posttraumatic stress disorder in female victims of interpersonal violence. Journal of Consulting and Clinical Psychology, 76(2), 243-258.

Resick, P. A., Williams, L. F., Suvak, M. K., Monson, C. M., \& Gradus, J. L. (2012). Long-Term Outcomes of Cognitive-Behavioral Treatments for Posttraumatic Stress Disorder Among Female Rape Survivors. Journal of Consulting and Clinical Psychology, 80(2), 201-210.

Resnick, H. S., Kilpatrick, D. G., Dansky, B. S., Saunders, B. E., \& Best, C. L. (1993). Prevalence of civilian trauma and posttraumatic stress disorder in a representative national sample of women. Journal of Consulting and Clinical Psychology, 61(6), 984991.

Resnick, H. S., Kilpatrick, D. G., Dansky, B. S., Saunders, B. E., \& Best, C. L. (1993). Prevalence of civilian trauma and posttraumatic stress disorder in a representative national sample of women. Journal of consulting and clinical psychology, 61(6), 984.

Robins, L. N., \& Helzer, J. E. (1985). Diagnostic Interview Schedule (DIS), Version III-A. Department of Psychiatry, Washington University School of Medicine.

Rosen, C. S., Chow, H. C., Finney, J. F., Greenbaum, M. A., Moos, R. H., Sheikh, J. I., \& Yesavage, J. A. (2004). VA practice patterns and practice guidelines for treating posttraumatic stress disorder. Journal of Traumatic Stress, 17(3), 213-222.

Rothbaum, B. O., Foa, E. B., Riggs, D. S., Murdock, T., \& Walsh, W. (1992). A prospective examination of post-traumatic stress disorder in rape victims. Journal of Traumatic Stress, 5(3), 455-475. 
Roy-Byrne, P., Berliner, L., Russo, J., Zatzick, D., \& Pitman, R. K. (2003). Treatment preferences and determinants in victims of sexual and physical assault. The Journal of Nervous And Mental Disease, 191(3), 161-165.

Ruggiero, K. J., Del Ben, K., Scotti, J. R., \& Rabalais, A. E. (2003). Psychometric properties of the PTSD Checklist-Civilian version. Journal of Traumatic Stress, 16(5), 495-502.

Sareen, J., Cox, B. J., Afifi, T. O., de Graaf, R., Asmundson, G. J., ten Have, M., \& Stein, M. B. (2005). Anxiety disorders and risk for suicidal ideation and suicide attempts: a population-based longitudinal study of adults. Archives of General Psychiatry, 62(11), 1249.

Seidler, G. H., \& Wagner, F. E. (2006). Comparing the efficacy of EMDR and trauma-focused cognitive-behavioral therapy in the treatment of PTSD: a meta-analytic study. Psychological Medicine, 36(11), 1515-1522.

Shore, J. H., Vollmer, W. M., \& Tatum, E. L. (1989). Community patterns of posttraumatic stress disorders. The Journal of Nervous and Mental Disease, 177(11), 681-685.

Sierles, F. S., Chen, J. J., McFarland, R. E., \& Taylor, M. A. (1983). Posttraumatic stress disorder and concurrent psychiatric illness: a preliminary report. The American Journal of Psychiatry, 140(9), 1177-1179.

Steckler, T., \& Risbrough, V. (2012). Pharmacological treatment of PTSD-established and new approaches. Neuropharmacology, 62(2), 617-627.

Stein, M. B., Kline, N. A., \& Matloff, J. L. (2002). Adjunctive olanzapine for SSRI-resistant combat-related PTSD: A double-blind, placebo-controlled study. American Journal of Psychiatry, 159(10), 1777-1779. 
Stein, M. B., Walker, J. R., Hazen, A. L., \& Forde, D. R. (1997). Full and partial posttraumatic stress disorder: findings from a community survey. American Journal of Psychiatry, 154(8), 1114-1119.

Tarrier, N., Pilgrim, H., Sommerfield, C., Faragher, B., Reynolds, M., Graham, E., \& Barrowclough, C. (1999). A randomized trial of cognitive therapy and imaginal exposure in the treatment of chronic posttraumatic stress disorder. Journal Of Consulting And Clinical Psychology, 67(1), 13-18.

van Ameringen, M., Mancini, C., Patterson, B., \& Boyle, M. H. (2008). Post-Traumatic Stress Disorder in Canada. CNS neuroscience \& therapeutics, 14(3), 171-181.

van der Kolk, B. A., Dreyfuss, D., Michaels, M., \& Shera, D. (1994). Fluoxetine in posttraumatic stress disorder. Journal of Clinical psychiatry, 55(12), 517-522.

van Etten, M. L., \& Taylor, S. (1998). Comparative efficacy of treatments for post-traumatic stress disorder: a meta-analysis. Clinical Psychology and Psychotherapy, 5, 126-144.

Wunderlich, U., Bronisch, T., \& Wittchen, H. U. (1998). Comorbidity patterns in adolescents and young adults with suicide attempts. European Archives of Psychiatry and Clinical Neuroscience, 248(2), 87-95.

Zoellner, L. A., Feeny, N. C., \& Bittinger, J. N. (2009). What you believe is what you want: Modeling PTSD-related treatment preferences for sertraline or prolonged exposure. Journal of Behavior Therapy and Experimental Psychiatry,40(3), 455.

Zohar, J., Amital, D., Miodownik, C., Kotler, M., Bleich, A., Lane, R. M., \& Austin, C. (2002). Double-blind placebo-controlled pilot study of sertraline in military veterans with posttraumatic stress disorder. Journal of Clinical Psychopharmacology, 22(2), 190-195. 


\section{Appendix A.}

\section{Depression Anxiety Stress Scales (DASS-21):}

The following questions are designed to assess your levels of depression, anxiety, and general stress over the past week.

Please read each statement and circle a number $0,1,2$ or 3 which indicates how much the statement applied to you over the past week. There are no right or wrong answers.

Do not spend too much time on any statement.

The rating scale is as follows:

$0 \quad$ Did not apply to me at all

1 Applied to me to some degree, or some of the time

2 Applied to me to a considerable degree, or a good part of time

3 Applied to me very much, or most of the time

1 I found it hard to wind down

$\begin{array}{llll}0 & 1 & 2 & 3\end{array}$

2 I was aware of dryness of my mouth

$\begin{array}{llll}0 & 1 & 2 & 3\end{array}$

3 I couldn't seem to experience any positive feeling at all

$\begin{array}{llll}0 & 1 & 2 & 3\end{array}$

$4 \quad$ I experienced breathing difficulty (e.g., excessively rapid breathing, $\begin{array}{llllll}0 & 1 & 2 & 3\end{array}$ breathlessness in the absence of physical exertion) 
5 I found it difficult to work up the initiative to do things

$\begin{array}{llll}0 & 1 & 2 & 3 \\ 0 & 1 & 2 & 3 \\ 0 & 1 & 2 & 3 \\ 0 & 1 & 2 & 3 \\ 0 & 1 & 2 & 3\end{array}$
a fool of myself

10 I felt that I had nothing to look forward to

$\begin{array}{llll}0 & 1 & 2 & 3\end{array}$

11 I found myself getting agitated

$\begin{array}{llll}0 & 1 & 2 & 3\end{array}$

12 I found it difficult to relax

$\begin{array}{llll}0 & 1 & 2 & 3\end{array}$

13 I felt down-hearted and blue

$\begin{array}{llll}0 & 1 & 2 & 3\end{array}$

14 I was intolerant of anything that kept me from getting on with

$\begin{array}{llll}0 & 1 & 2 & 3\end{array}$ what I was doing

15 I felt I was close to panic

$\begin{array}{llll}0 & 1 & 2 & 3\end{array}$

16 I was unable to become enthusiastic about anything

$\begin{array}{llll}0 & 1 & 2 & 3\end{array}$

17 I felt I wasn't worth much as a person

$\begin{array}{llll}0 & 1 & 2 & 3\end{array}$

18 I felt that I was rather touchy

$\begin{array}{llll}0 & 1 & 2 & 3\end{array}$

19 I was aware of the action of my heart in the absence of physical

$\begin{array}{llll}0 & 1 & 2 & 3\end{array}$ exertion (e.g., sense of heart rate increase, heart missing a beat) 
20 I felt scared without any good reason

21 I felt that life was meaningless $\begin{array}{llll}0 & 1 & 2 & 3\end{array}$

$\begin{array}{llll}0 & 1 & 2 & 3\end{array}$ 


\section{Appendix B.}

\section{Life Events Checklist (LEC):}

Listed below are a number of difficult or stressful things that sometimes happen to people. For each event check one or more of the boxes to the right to indicate that:

(a) it happened to you personally,

(b) you witnessed it happen to someone else,

(c) you learned about it happening to someone close to you,

(d) you're not sure if it fits, or (e) it doesn't apply to you.

Be sure to consider your entire life (growing up as well as adulthood) as you go through the list of events.

\begin{tabular}{|l|l|l|l|l|l|}
\hline & $\begin{array}{c}\text { Happened } \\
\text { Personally } \\
\text { (a) }\end{array}$ & $\begin{array}{c}\text { Witnesse } \\
\mathrm{d} \text { It } \\
\text { (b) }\end{array}$ & $\begin{array}{c}\text { Learned } \\
\text { About it } \\
\text { (c) }\end{array}$ & $\begin{array}{c}\text { Not Sure } \\
\text { (d) }\end{array}$ & $\begin{array}{c}\text { Apply } \\
\text { (e) }\end{array}$ \\
\hline Natural disaster & & & & & \\
\hline Fire or explosion & & & & & \\
\hline Transportation accident & & & & & \\
\hline Serious accident & & & & & \\
\hline Exposure to toxic substance & & & & & \\
\hline Physical assault & & & & & \\
\hline Assault with a weapon & & & & & \\
\hline Sexual assault & & & & & \\
\hline $\begin{array}{l}\text { Other unwanted or } \\
\text { uncomfortable sexual experience }\end{array}$ & & & & & \\
\hline Combat or exposure to a war & & & & & \\
\hline
\end{tabular}




\begin{tabular}{|l|l|l|l|l|l|}
\hline zone & & & & & \\
\hline Captivity & & & & & \\
\hline Life-threatening illness or injury & & & & & \\
\hline Severe human suffering & & & & & \\
\hline Sudden, violent death & & & & & \\
\hline $\begin{array}{l}\text { Sudden, unexpected death of } \\
\text { someone close to you }\end{array}$ & & & & & \\
\hline $\begin{array}{l}\text { Serious injury, harm, or death } \\
\text { you caused to someone else }\end{array}$ & & & & & \\
\hline $\begin{array}{l}\text { Another very stressful event or } \\
\text { experience }\end{array}$ & & & & & \\
\hline
\end{tabular}




\section{Appendix C.}

\section{PTSD Checklist - Specific (PCL-S):}

Below is a list of problems and complaints that people sometimes have in response to stressful life experiences.

Please read each one carefully, then choose one of the numbers to the right to indicate how much you have been bothered by the problem in the past month.

\begin{tabular}{|c|c|c|c|c|c|}
\hline & $\begin{array}{c}\text { Not at all } \\
\text { (1) }\end{array}$ & $\begin{array}{l}\text { A little } \\
\text { bit } \\
\text { (2) }\end{array}$ & $\begin{array}{l}\text { Moderat } \\
\text { ely } \\
\text { (3) }\end{array}$ & $\begin{array}{l}\text { Quite a } \\
\text { bit } \\
\text { (4) }\end{array}$ & $\begin{array}{c}\text { Extremel } \\
\qquad \begin{array}{c}\text { y } \\
(5)\end{array}\end{array}$ \\
\hline $\begin{array}{l}\text { 1. Repeated, disturbing memories, } \\
\text { thoughts, or images of a stressful } \\
\text { experience from the past? }\end{array}$ & & & & & \\
\hline $\begin{array}{l}\text { 2. Repeated, disturbing dreams of a } \\
\text { stressful experience from the past? }\end{array}$ & & & & & \\
\hline $\begin{array}{l}\text { 3. Suddenly acting or feeling as if a } \\
\text { stressful experience were happening } \\
\text { again (as if you were reliving it)? }\end{array}$ & & & & & \\
\hline $\begin{array}{l}\text { 4. Feeling very upset when } \\
\text { something reminded you of a }\end{array}$ & & & & & \\
\hline
\end{tabular}




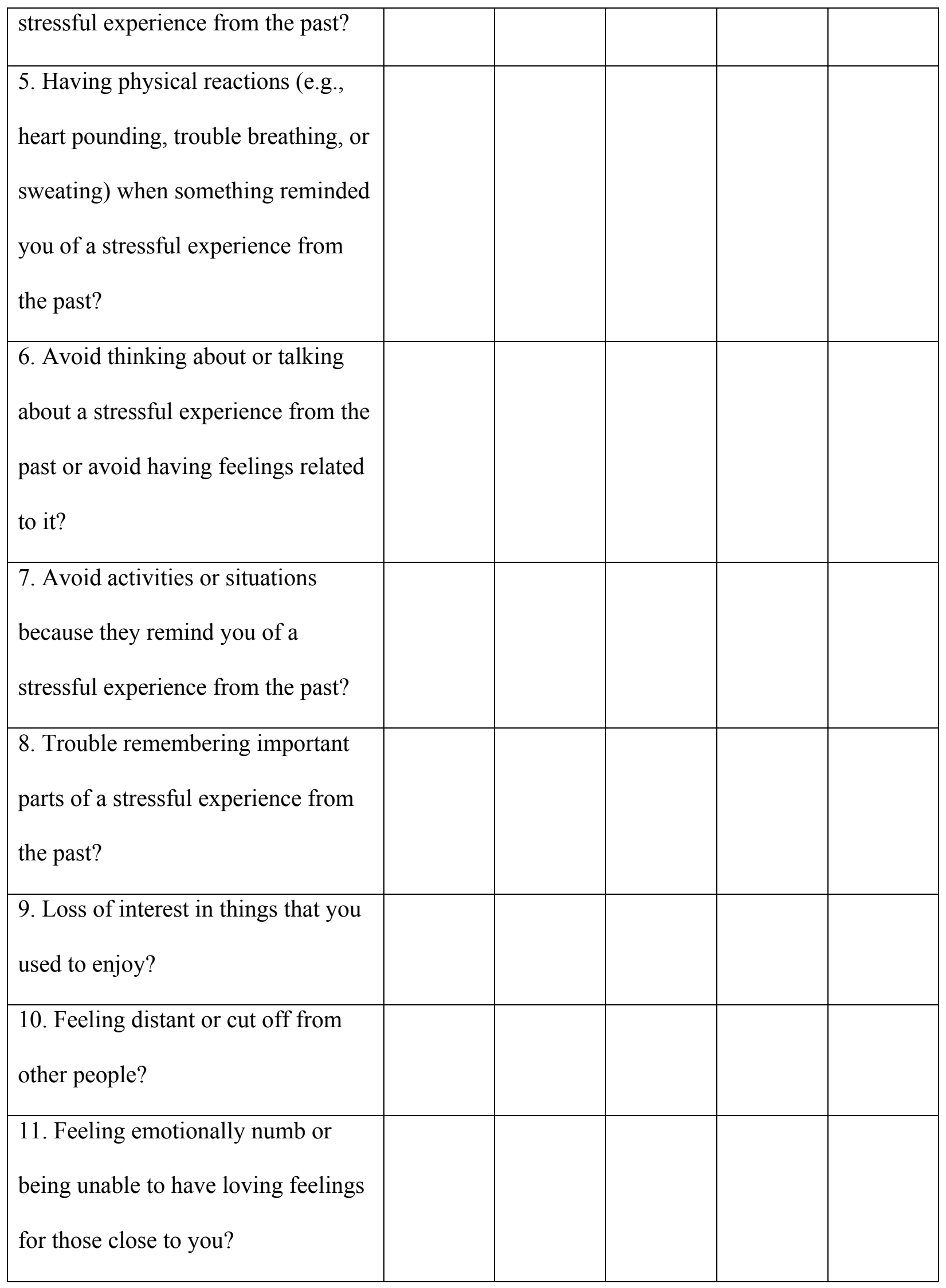




\begin{tabular}{|l|l|l|l|l|l|}
\hline 12. Feeling as if your future will & & & & & \\
somehow be cut short? & & & & & \\
asleep? & & & & & \\
\hline 14. Feeling irritable or having angry & & & & & \\
outbursts? & & & & & \\
\hline 15. Having difficulty concentrating? & & & & & \\
\hline Being "super alert" or watchful on & & & & & \\
guard? & & & & & \\
\hline 16. Feeling jumpy or easily startled? & & & & & \\
\hline
\end{tabular}




\section{Appendix D.}

\section{Cognitive Therapy (CT):}

Cognitive Therapy (CT) is a treatment for PTSD that requires 12 sessions of individual psychotherapy, where sessions are 50 minutes long. Cognitive Therapy has been thoroughly tested and evaluated, and we know that it can significantly reduce PTSD and depression symptoms.

In Cognitive Therapy, you learn to identify your thoughts about the traumatic event so that they cause you less distress. You will also learn to identify current day thoughts about the world and yourself that make you feel afraid or upset, and to replace these with more accurate and less distressing thoughts.

Cognitive Therapy is based on the idea that after a trauma, people may experience shame, guilt, and negative thoughts about themselves, others, and the world. While these thoughts can be used to help make sense of the world after trauma, they may also cause them to continue having symptoms of PTSD.

By more carefully considering your thoughts about the trauma and current thoughts influenced by the trauma, you have the opportunity to gain a healthier understanding of the trauma and its effects.

Cognitive Therapy with your therapist will include:

- Education about PTSD symptoms 
- Education about common emotional reactions and changes in beliefs about oneself, others, and the world, after a traumatic event

- Writing about the traumatic event and reading it out loud

- As homework, doing readings and worksheets that challenge your thoughts about the trauma, so that they become less unrealistic or one-sided than they are now.

- Challenging unrealistic or one-sided thoughts, with your therapist, concerning issues such as how safe one really is in the world, trusting oneself and others, how much power/control we have over life events, self-esteem, and intimacy.

The risks associated with $\mathrm{CT}$ are mild to moderate discomfort when exposed to anxietyprovoking thoughts and feelings.

\section{Exposure Therapy (ET):}

Exposure Therapy (ET) is a treatment for PTSD that requires 9-12 sessions of individual psychotherapy, where sessions are 90 minutes long. Exposure Therapy has been thoroughly tested and evaluated, and we know that it can significantly reduce PTSD and depression symptoms.

In Exposure Therapy, you talk about the traumatic event repeatedly, with a therapist, until it causes you less distress. You will also do things in your daily life that you have been avoiding, which remind you of the trauma and make you feel afraid or upset, so that you become less distressed by them over time. 
Exposure Therapy is based on the idea that after a trauma, people learn to fear and then avoid thoughts, feelings, and situations that remind them of the trauma. While avoiding helps people feel better for a little while, it may also cause them to continue having symptoms of PTSD.

Exposure Therapy helps you gain more control over the emotions, thoughts, and feelings related to the traumatic event you lived through, by having you talk about your trauma repeatedly with a therapist.

Exposure Therapy with your therapist will include:

- Education about PTSD symptoms

- Education about common emotional reactions and changes in beliefs about oneself, others, and the world, after a traumatic event.

- Breathing or Relaxation Training

- As homework, slowly exposing yourself to situations that remind you of the trauma so that they become less scary than they are now.

- Repeatedly revisiting the memory of the trauma, with your therapist, to try and make sense of it and have it become less distressing over time.

The risks associated with Exposure Therapy are mild to moderate discomfort when exposed to anxiety-provoking images, situations, and places. 


\section{Medication Therapy (MT):}

Medication Therapy (MT) is a treatment for PTSD that requires regular visits with your physician, where visits are 15-30 minutes long. Medication Therapy has been thoroughly tested and evaluated, and we know that it can significantly reduce PTSD and depression symptoms.

In Medication Therapy, you explain the symptoms that you are currently experiencing related to the traumatic event, so that your symptoms can be eased to cause you less distress. You will take medication daily so that you sleep better, feel less afraid or upset, and become less distressed over time.

Medication Therapy is based on the idea that medications gradually affect the chemicals in the brain. These changes can cause PTSD symptoms to improve. While people can cope with the symptoms of PTSD for a little while, not seeking medical help can cause them to continue having symptoms of PTSD.

Medication Therapy will help you feel less distressed by reducing the symptoms of PTSD once you tell your physician about the trauma and the symptoms you are having and using the medication you and your doctor agree to use.

Medication Therapy with your physician will include:

- Telling your psychiatrist about your PTSD symptoms, other health-related symptoms, and the trauma. 
- Education about PTSD symptoms, medication options, potential benefits and side effects, and medical conditions that commonly co-occur with PTSD.

- Understanding that medications might not work as soon as you start, but they will work as fast as psychotherapy.

- Meeting with a physician about once every 2-4 weeks at first and then every 3-6 months if you are doing well.

- Talking with your physician about the benefits and side effects you are experiencing and working together to change the medication type and/or dose if necessary to achieve maximum benefits and minimum side effects.

The risks associated with Medication Therapy are mild to moderate side effects or withdrawal symptoms that are different for each medication and do not occur in all patients, such as weight gain or loss, loose stools, sweating, nausea, headache, fatigue, loss of appetite, sexual impairment, increased anxiety, restlessness, and insomnia. 


\section{Appendix E.}

\section{Credibility Scale (CS):}

\begin{tabular}{|c|c|c|c|c|c|}
\hline & $\begin{array}{c}\text { Not at all } \\
\text { (1) }\end{array}$ & $\begin{array}{l}\text { A little bit } \\
\text { (2) }\end{array}$ & $\begin{array}{c}\text { Moderatel } \\
\text { (3) }\end{array}$ & $\begin{array}{l}\text { Quite a bit } \\
\text { (4) }\end{array}$ & $\begin{array}{l}\text { Extremely } \\
\text { (5) }\end{array}$ \\
\hline $\begin{array}{l}\text { 1. How logical does this therapy } \\
\text { seem to you? }\end{array}$ & & & & & \\
\hline $\begin{array}{l}\text { 2. How scientific does this therapy } \\
\text { seem to you? }\end{array}$ & & & & & \\
\hline $\begin{array}{l}\text { 3. How complete does this therapy } \\
\text { seem to you? In other words, do yo } \\
\text { think this therapy covers all the } \\
\text { types of people who develop PTSD }\end{array}$ & & & & & \\
\hline $\begin{array}{l}\text { 4. To what extent would this therap } \\
\text { help an individual in other areas of } \\
\text { his or her life? }\end{array}$ & & & & & \\
\hline $\begin{array}{l}\text { 5. How likely would you be to go } \\
\text { into this therapy if you had PTSD? }\end{array}$ & & & & & \\
\hline $\begin{array}{l}\text { 6. How effective do you think this } \\
\text { therapy would be for most people? }\end{array}$ & & & & & \\
\hline $\begin{array}{l}\text { 7. If a close friend or relative had } \\
\text { PTSD, would you recommend this } \\
\text { therapy to them? }\end{array}$ & & & & & \\
\hline
\end{tabular}




\section{Appendix F.}

Personal Reactions to the Rationales (PRR):

\begin{tabular}{|c|c|c|c|c|c|}
\hline & $\begin{array}{c}\text { Not at all } \\
\text { (1) }\end{array}$ & $\begin{array}{c}\text { A little bit } \\
\text { (2) }\end{array}$ & $\begin{array}{c}\text { Moderatel } \\
\text { (3) }\end{array}$ & $\begin{array}{c}\text { Quite a bit } \\
\text { (4) }\end{array}$ & $\begin{array}{c}\text { Extremely } \\
\text { (5) }\end{array}$ \\
\hline $\begin{array}{l}\text { 1. If you had PTSD and went to see } \\
\text { a therapist, how helpful do you think } \\
\text { this therapy would be for you? }\end{array}$ & & & & & \\
\hline $\begin{array}{l}\text { 2. To what extent do you think that } \\
\text { this therapy would help you to } \\
\text { understand the causes of your } \\
\text { PTSD? }\end{array}$ & & & & & \\
\hline $\begin{array}{l}\text { 3. To what extent do you think that } \\
\text { this therapy would help you learn } \\
\text { effective ways to cope with your } \\
\text { PTSD symptoms? }\end{array}$ & & & & & \\
\hline $\begin{array}{l}\text { 4. If you were to seek therapy for } \\
\text { PTSD, how likely would you be to } \\
\text { choose this type of therapy? }\end{array}$ & & & & & \\
\hline $\begin{array}{l}\text { 5. If you were to try this type of } \\
\text { therapy, how effective would it be in } \\
\text { treating your PTSD? }\end{array}$ & & & & & \\
\hline
\end{tabular}

